\title{
GLACE: The Global Land-Atmosphere Coupling Experiment. Part I: Overview
}

\author{
Randal D. Koster, ${ }^{\mathrm{a}}$ Zhichang Guo, ${ }^{\mathrm{b}}$ Paul A. Dirmeyer, ${ }^{\mathrm{b}}$ Gordon Bonan, ${ }^{\mathrm{c}}$ Edmond Chan, ${ }^{\mathrm{d}}$ \\ Peter Cox,${ }^{\mathrm{e}}$ Harvey Davies, ${ }^{\mathrm{f}}$ C. T. Gordon, ${ }^{\mathrm{g}}$ Shinjiro Kanae, ${ }^{\mathrm{h}}$ Eva Kowalczyk,${ }^{\mathrm{f}}$ \\ David Lawrence, ${ }^{\mathrm{i}}$ Ping Liu ${ }^{\mathrm{j}}$ Cheng-Hsuan Lu, ${ }^{\mathrm{k}}$ Sergey Malyshev, ${ }^{1}$ Bryant McAvaney, ${ }^{\mathrm{m}}$ \\ Ken Mitchell, ${ }^{\mathrm{k}}$ David Mocko, ${ }^{\mathrm{j}}$ Taikan Oki, ${ }^{\mathrm{n}}$ Keith W. Oleson, ${ }^{\mathrm{c}}$ Andrew Pitman, ${ }^{\mathrm{o}}$ Y. C. Sud, ${ }^{\mathrm{a}}$ \\ Christopher M. TAylor, ${ }^{\mathrm{p}}$ Diana Verseghy, ${ }^{\mathrm{d}}$ RatKo Vasic, ${ }^{\mathrm{q}}$ Yongkang Xue, ${ }^{\mathrm{q}}$ AND \\ TOMOHITO YAMADA ${ }^{\mathrm{n}}$
}

\author{
${ }^{a}$ NASA Goddard Space Flight Center, Greenbelt, Maryland \\ ${ }^{\mathrm{b}}$ Center for Ocean-Land-Atmosphere Studies, Calverton, Maryland \\ ${ }^{\mathrm{c}}$ National Center for Atmospheric Research, Boulder, Colorado \\ ${ }^{\mathrm{d}}$ Meteorological Service of Canada, Toronto, Ontario, Canada \\ ${ }^{\mathrm{e}}$ Centre for Ecology and Hydrology, Dorset, Dorset, United Kingdom \\ ${ }^{\mathrm{f}}$ CSIRO Atmospheric Research, Aspendale, Victoria, Australia \\ ${ }^{\mathrm{g}}$ Geophysical Fluid Dynamics Laboratory, Princeton, New Jersey \\ ${ }^{\mathrm{h}}$ Research Institute for Humanity and Nature, Kyoto, Japan \\ ${ }^{\mathrm{i}}$ University of Reading, Reading, Berkshire, United Kingdom \\ ${ }^{\mathrm{j}}$ Science Applications International Corporation, Beltsville, Maryland \\ ${ }^{\mathrm{k}}$ National Centers for Environmental Prediction, Camp Springs, Maryland \\ ${ }^{1}$ Princeton University, Princeton, New Jersey \\ ${ }^{\mathrm{m}}$ Bureau of Meteorology Research Centre, Melbourne, Victoria, Australia \\ ${ }^{\mathrm{n}}$ University of Tokyo, Tokyo, Japan \\ ${ }^{\circ}$ Macquarie University, North Ryde, New South Wales, Australia \\ ${ }^{\mathrm{p}}$ Centre for Ecology and Hydrology, Wallingford, Oxfordshire, United Kingdom \\ ${ }^{\mathrm{q}}$ University of California, Los Angeles, Los Angeles, California
}

(Manuscript received 5 April 2005, in final form 31 October 2005)

\begin{abstract}
The Global Land-Atmosphere Coupling Experiment (GLACE) is a model intercomparison study focusing on a typically neglected yet critical element of numerical weather and climate modeling: landatmosphere coupling strength, or the degree to which anomalies in land surface state (e.g., soil moisture) can affect rainfall generation and other atmospheric processes. The 12 AGCM groups participating in GLACE performed a series of simple numerical experiments that allow the objective quantification of this element for boreal summer. The derived coupling strengths vary widely. Some similarity, however, is found in the spatial patterns generated by the models, with enough similarity to pinpoint multimodel "hot spots" of land-atmosphere coupling. For boreal summer, such hot spots for precipitation and temperature are found over large regions of Africa, central North America, and India; a hot spot for temperature is also found over eastern China. The design of the GLACE simulations are described in full detail so that any interested modeling group can repeat them easily and thereby place their model's coupling strength within the broad range of those documented here.
\end{abstract}

\section{Introduction}

\section{a. Motivation}

Precipitation has a clear impact on soil moisture: large rain events tend to wet the soil. To what extent,

Corresponding author address: Randal Koster, NASA GFSC, Code 610.1, Greenbelt, MD 20771.

E-mail: randal.d.koster@nasa.gov though, do land surface moisture and temperature states affect, in turn, the evolution of weather and the generation of precipitation? How does a humaninduced change in land cover affect local and remote weather, if at all? Such questions lie at the heart of much recent climatological research. This research is largely performed with numerical models of global weather and climate [atmospheric general circulation models (AGCMs)], mostly because direct observations 
of the impact of land surface anomalies on atmospheric behavior are difficult, if not impossible, to obtain at regional to continental scales. Also, AGCMs have the advantage of being amenable to sensitivity studiestheir process parameterizations can be manipulated easily in controlled experiments.

The list of published AGCM studies that address questions of land-climate interaction is extensive (e.g., Charney et al. 1977; Shukla and Mintz 1982; Henderson-Sellers and Gornitz 1984; Delworth and Manabe 1989; Oglesby and Erickson 1989; Dirmeyer 1994; Lau and Bua 1998; Xue et al. 2001, 2004; to name only a small fraction). Generally missing from these studies, however, is an analysis of the degree to which the experimental results are model dependent. Such model dependence can bias results tremendously. Consider two hypothetical AGCMs, one in which the atmosphere responds strongly to anomalies in surface fluxes, which in turn respond to anomalies in land surface state, and one in which the atmosphere has an internal variability (chaotic dynamics) that overwhelms any signal from the land surface. (Note that in this paper, the term "land surface" refers to the combination of the vegetation canopy, the soil-atmosphere interface, and the top few meters or so of the soil, as typically modeled by AGCMs.) Experiments with these two AGCMs would lead to contradictory conclusions about the importance of properly initializing soil moisture in forecast simulations, about the degree to which deforestation affects climate, and perhaps even about the need for a realistic treatment of land surface processes in climate simulations. Contradictory results regarding land-atmosphere interaction do pervade the literature; see, for example, the broad range of results on deforestation outlined by Hahmann and Dickinson (1997).

The degree to which the atmosphere responds to anomalies in land surface state in a consistent manner, particularly at daily to seasonal time scales, is hereafter loosely referred to as the "land-atmosphere coupling strength." This coupling strength cannot be determined a priori from a look at the model's computer code. It is not explicitly prescribed or parameterized; it is, rather, a net result of complex interactions between numerous complex process parameterizations in the AGCM, such as those for evapotranspiration, boundary layer development, and moist convection. Arguably, a shortcoming in the analysis of the model-generated climate system is that this coupling strength, though a fundamental element of the system, is rarely examined closely and is almost never objectively quantified. The great majority of AGCM land-atmosphere interaction studies do not address the realism of the coupling strength implicit in the model used or how it compares with that in other models.

An objective quantification and documentation of the coupling strength across a broad range of models would be valuable, if only to serve as a frame of reference when interpreting the experimental results of any particular model. This objective documentation and quantification is indeed the goal of the Global LandAtmosphere Coupling Experiment (GLACE). GLACE ("glah-say") aims to show the extent to which coupling strength varies between models, and, more importantly, to characterize individual models as having a relatively strong, intermediate, or weak coupling, for later use in interpreting various results obtained with those models. The range of coupling strengths uncovered by GLACE serves to quantify the uncertainty inherent in our understanding of land-atmosphere coupling and our ability to model it.

\section{b. Relationship to pilot study}

GLACE is a broad follow on to the four-model intercomparison study of Koster et al. (2002, hereafter referred to as K02). K02 describes a numerical experiment performed by four independent AGCM modeling groups, an experiment that quantified, for each of the models, the degree to which precipitation responds consistently to a prescribed model-consistent time series of land surface prognostic states. The chief result of K02 was a marked disparity in the coupling strengths of the four models.

GLACE extends the K02 study substantially, as follows:

Participation from a wider range of models: The intriguing intermodel variations discovered by $\mathrm{K} 02$ are presumably indicative of a broad range of coupling strengths implicit in today's AGCMs. The goal of GLACE is to establish this range more precisely and (more importantly) to generate a comprehensive "table" of AGCM coupling strengths that can help in the interpretation of the published results of a wide variety of climate models.

Separation of the effects of "fast" and "slow" reservoirs: The experimental setup used in K02 was limited; the prescribed diurnal surface temperature variations appeared to have had as much an effect on coupling strength as anything else. Because the initialization of surface temperature and water amounts in fast moisture reservoirs (e.g., canopy interception) have little potential for prediction, particularly at subseasonal time scales and longer, the differences uncovered by $\mathrm{K} 02$ may have lim- 
ited practical application. Of much greater relevance to many land impact questions is whether some of the slower state variables-those variables with significant "memory" (in particular, soil moisture in the root zone and deeper reservoirs) - have an impact on the evolution of weather. This aspect of coupling strength is a major focus of GLACE.

Effect on air temperature: K02 focused on how the land surface boundary affects the generation of precipitation. Also of interest is the control of the land boundary on air temperature fluctuations, particularly when only root zone (and lower) soil moisture is prescribed. GLACE provides the means to address this issue.

GLACE can indeed claim participation from a wider range of models. The experiment was offered to the community in early 2003. Over the course of that year, 12 AGCM groups performed the experiment and submitted results for processing.

\section{c. Focus of paper}

The purpose of the present paper is twofold. First, it thoroughly describes and contrasts the inherent coupling strengths of the 12 participating models. It thus provides a "snapshot" of the current state of landatmosphere modeling, with emphasis (unlike K02) on the impacts of the slow reservoirs that are relevant to seasonal prediction. Second, and perhaps more important, it provides a full set of instructions for performing the experiments. This will allow additional models or future versions of the participating models to repeat them at will and immediately place their model's behavior in the context of the behaviors documented herein. A companion paper (Guo et al. 2006, hereafter Part II) examines the model-to-model differences in coupling strength, and the spatial variations in coupling strength seen within a given model, in the context of parameterization differences and differences in the climatological and hydrological regimes.

Neither paper, however, addresses the realism of simulated coupling strength, primarily because direct measurements of land-atmosphere interaction at large scales do not exist. The identification of the proper measurements to be made and their subsequent collection and analysis would clearly advance the study of this interaction. Potential local assessments of coupling strength and indirect large-scale evaluations are reserved for a future study.

In addition, GLACE is not truly "global" in the sense that Southern Hemisphere midlatitudes are not properly represented. Coupling strength should be highest during summer, when evaporation rates are highest.
GLACE utilized boreal summer simulations because most of Earth's landmass is in the Northern Hemisphere. The potential for the appearance of different patterns of coupling strength during austral summer should be kept in mind when examining the results herein.

In the present paper, the experimental design is described in section 2, with technical details relegated to an appendix. Section 3 provides an overview of the participating models. Section 4 presents the basic results, and section 5 provides a look at where on the globe the models tend to agree.

\section{Experimental design}

GLACE consists of three separate 16-member ensembles of AGCM simulations, each simulation covering the period of 1 June-31 August. In central processing unit (CPU) terms, this is equivalent to a single 12-yr AGCM simulation. The overall design of the experiments is illustrated in Fig. 1, and the run specifications are summarized in Table 1.

The first ensemble, called ensemble W (for "write," because the prognostic variable information from one of the member simulations is written to a file), is essentially a standard set of AGCM simulations with prescribed sea surface temperatures. Because of chaos in the climate system, of course, the land surface prognostic variables in the different simulations in ensemble W evolve differently, and in any case are initialized differently, to reflect the potentially broad range of initial values that are consistent with the system (see the appendix section 1b.) The only unusual aspect of this ensemble is that in one of the simulations, chosen randomly but referred to here as "W1" for convenience, all land prognostic variables are recorded into a special data file at every time step (see top panel of Fig. 1). The special data file is hereafter referred to as W1_STATES. The recorded prognostic variables include soil moisture contents at all vertical levels, temperatures at all vertical levels, canopy interception reservoir content, and various variables characterizing snow, if snow is present. One global field is recorded per state variable per time step. K02, by the way, demonstrated that the choice of the ensemble member used to write into W1_STATES is unimportant (at least for the one model examined); on a global average, any ensemble member should produce approximately the same results in the later parts of the experiment.

The second part of the experiment consists of another 16-member ensemble of 3-month simulations, using the same prescribed SSTs and the same 16 sets of atmospheric initial conditions. In this ensemble (here- 
Part 1: Ensemble W (16 members)

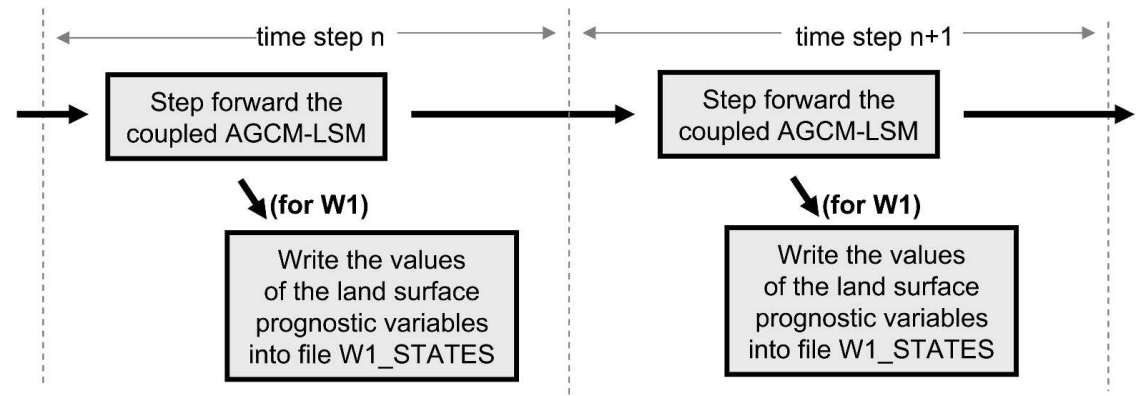

Part 2: Ensemble R (16 members)

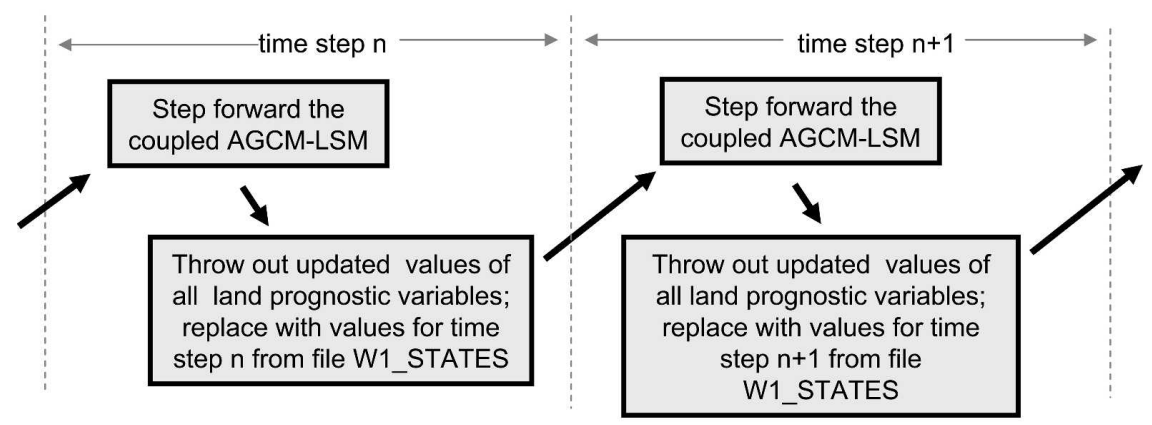

Part 3: Ensemble S (16 members)

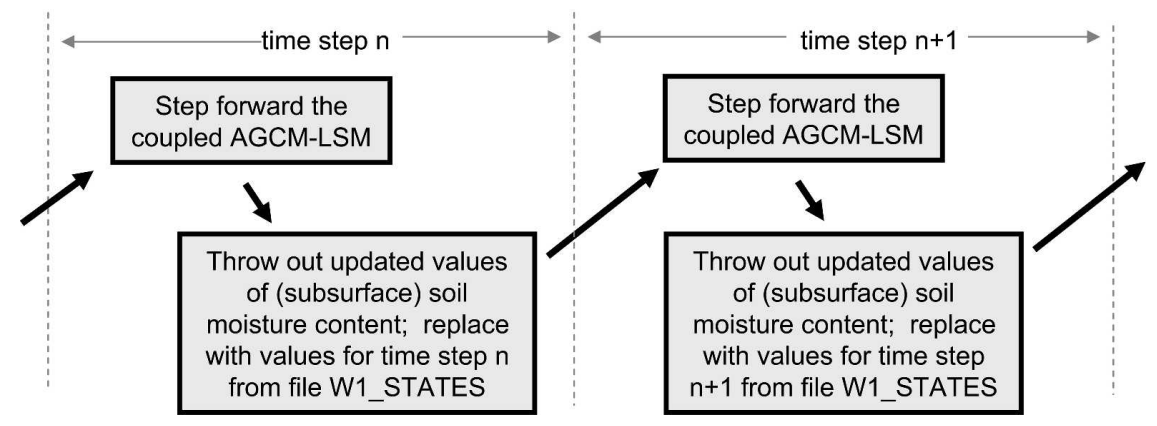

FIG. 1. Basic design of the experiment, as performed by all participating models.

after referred to as ensemble $\mathrm{R}$, where $\mathrm{R}$ stands for "read," because the land prognostic variable information is read from a file), all member simulations are forced to maintain precisely the same time series of (geographically varying) land surface states, namely, the states generated in simulation W1. If, for example, simulation W1 produced very wet soil in southern France on 27 July, then the atmosphere in every simu-

TABLE 1. Brief summary of GLACE ensembles.

\begin{tabular}{|c|c|c|c|c|}
\hline $\begin{array}{l}\text { Ensemble } \\
\text { identifier }\end{array}$ & $\begin{array}{c}\text { Ensemble } \\
\text { size }\end{array}$ & Integration period & Description & Key diagnostic \\
\hline $\mathrm{W}$ & 16 & 1 Jun-31 Aug 1994 & $\begin{array}{l}\text { Standard AGCM simulations with fully } \\
\text { interactive land surface model }\end{array}$ & $\begin{array}{l}\Omega(W) \text { : fraction of variance "explained" } \\
\text { (forced) by all boundary and initial } \\
\text { conditions }\end{array}$ \\
\hline $\mathrm{R}$ & 16 & 1 Jun-31 Aug 1994 & $\begin{array}{l}\text { As for } \mathrm{W} \text {, except all land state variables } \\
\text { at all depths are replaced at every } \\
\text { time step with values from file }\end{array}$ & $\begin{array}{l}\Omega(R)-\Omega(W) \text { : fraction of variance } \\
\quad \text { explained by prescription of all land } \\
\text { surface state variables }\end{array}$ \\
\hline$S$ & 16 & 1 Jun-31 Aug 1994 & $\begin{array}{l}\text { As for } \mathrm{W} \text {, except root zone and lower } \\
\text { soil moisture variables are replaced at } \\
\text { every time step with values from file }\end{array}$ & $\begin{array}{l}\Omega(S)-\Omega(W) \text { : fraction of variance } \\
\quad \text { explained by prescription of subsurface } \\
\text { soil moisture variables }\end{array}$ \\
\hline
\end{tabular}


lation of ensemble $\mathrm{R}$ is forced to feel the same very wet soil in southern France on 27 July. This effect is achieved by discarding, at every time step of every $\mathrm{R}$ simulation, the updated values of all land surface prognostic variables and then replacing them with the corresponding values for that time step from W1_STATES (see middle panel of Fig. 1).

The final part of the experiment, referred to as ensemble S (for "subsurface"), is equivalent to ensemble $\mathrm{R}$, except that only a small subset of the land surface prognostic variables are reset at each time step, as illustrated in the bottom panel of Fig. 1. In particular, only soil moistures corresponding to soil layers with centers $5 \mathrm{~cm}$ or more below the surface are reset from W1_STATES. The other variables (e.g., temperatures, canopy interception contents, and soil moisture in a thin surface layer, if such a layer exists) are allowed to evolve freely, as they did in ensemble W. Note that all models have soil moisture reservoirs that extend through the root zone (of the order of a meter), and sometimes further down. Most of the analysis in this paper and that in Part II will focus on this ensemble, because it isolates and quantifies the impact of a relatively predictable state [deep soil moisture: a state with significant inertia and memory (Koster and Suarez 2001)] on the evolution of weather.

SST boundary conditions for all of the integrations correspond, as much as possible, to the period of JuneAugust 1994. This year was chosen because neither El Niño nor La Niña conditions during the year are strong. Different SST datasets are available, but for consistency, modeling groups were asked to use the Atmospheric Model Intercomparison Project (AMIP)-2 SST dataset (Gleckler 1996) if at all possible. The K02 study, by the way, suggests that the impact of the chosen SST field on overall land-atmosphere coupling strength is small, though the choice of the year may perhaps have some bearing on specific geographical details.

Specific details of the experimental design, including rules for initialization of the different ensemble members, are provided in the appendix.

\section{Participating models}

Twelve AGCMs participated in the experiment. They are labeled (sometimes with the name of their home institutions) as follows: the Bureau of Meteorology Research Center (BMRC) in Melbourne, Australia; Canadian Centre for Climate Modelling and Analysis (CCCma), in Toronto, Ontario, Canada; Center for Climate System Research (CCSR)/National Institute for Environmental Studies (NIES), in Tokyo, Japan; the Center for Ocean-Land-Atmosphere Studies
(COLA), in Calverton, Maryland; Commonwealth Scientific and Industrial Research Organization (CSIRO)CC3, in Aspendale, Victoria, Australia; the Goddard Earth Observing System (GEOS)-Climate and Radiation Branch (CRB), an AGCM used at the Goddard Space Flight Center in Greenbelt, Maryland; the Geophysical Fluid Dynamics Laboratory (GFDL) in Princeton, New Jersey; Hadley Centre Atmosphere Model (HadAM) 3, an AGCM used at the Hadley Center for Climate Prediction and Research in Exeter, United Kingdom; the Community Atmosphere Model, version 3 (CAM3), used at the National Center for Atmospheric Research in Boulder, Colorado; the Global Forecast System Model (GFS)/Oregon State University land surface model (OSU), used at the National Centers for Environmental Prediction in Camp Springs, Maryland; the National Aeronautics and Space Administration (NASA) Seasonal-to-Interannual Prediction Project (NSIPP), now part of the Global Modeling and Assimilation Office at the Goddard Space Flight Center in Greenbelt, Maryland; and the University of California, Los Angeles (UCLA), in Los Angeles, California. Table 2 lists important details regarding the implementation of each of these models.

\section{Results}

\section{a. Precipitation}

Using the $\Omega$ diagnostic defined by K02, we examine here the land surface's control on "synoptic scale" precipitation variability, that is, the variability of precipitation on time scales of about a week. First, we aggregate the precipitation output from each simulation into time series of 6-day totals. Given that the simulations are 92 days long, and that we ignore the first 8 days to avoid problems associated with initial "shocks" to the modeled atmosphere, each simulation provides a time series $P(t)$ consisting of 14 six-day totals. For a given ensemble, which consists of 16 simulations, the temporal standard deviation of precipitation $\sigma_{P}$ at each grid cell is computed across the resulting 224 six-day totals. (The choice of 6 days for the time aggregation is arbitrary; other choices give similar results.) $\hat{P}(t)$,

Next, we compute the ensemble mean time series

$$
\hat{P}(t)=\frac{1}{16} \sum_{i=1}^{16} P_{i}(t),
$$

where $i$ represents the index of the ensemble member. The 14 values in $\hat{P}(t)$ are used to compute the standard deviation of the ensemble mean time series $\sigma_{\hat{P}}$. Finally, $\sigma_{P}$ and $\sigma_{\hat{P}}$ are combined into the diagnostic $\Omega_{P}$, 


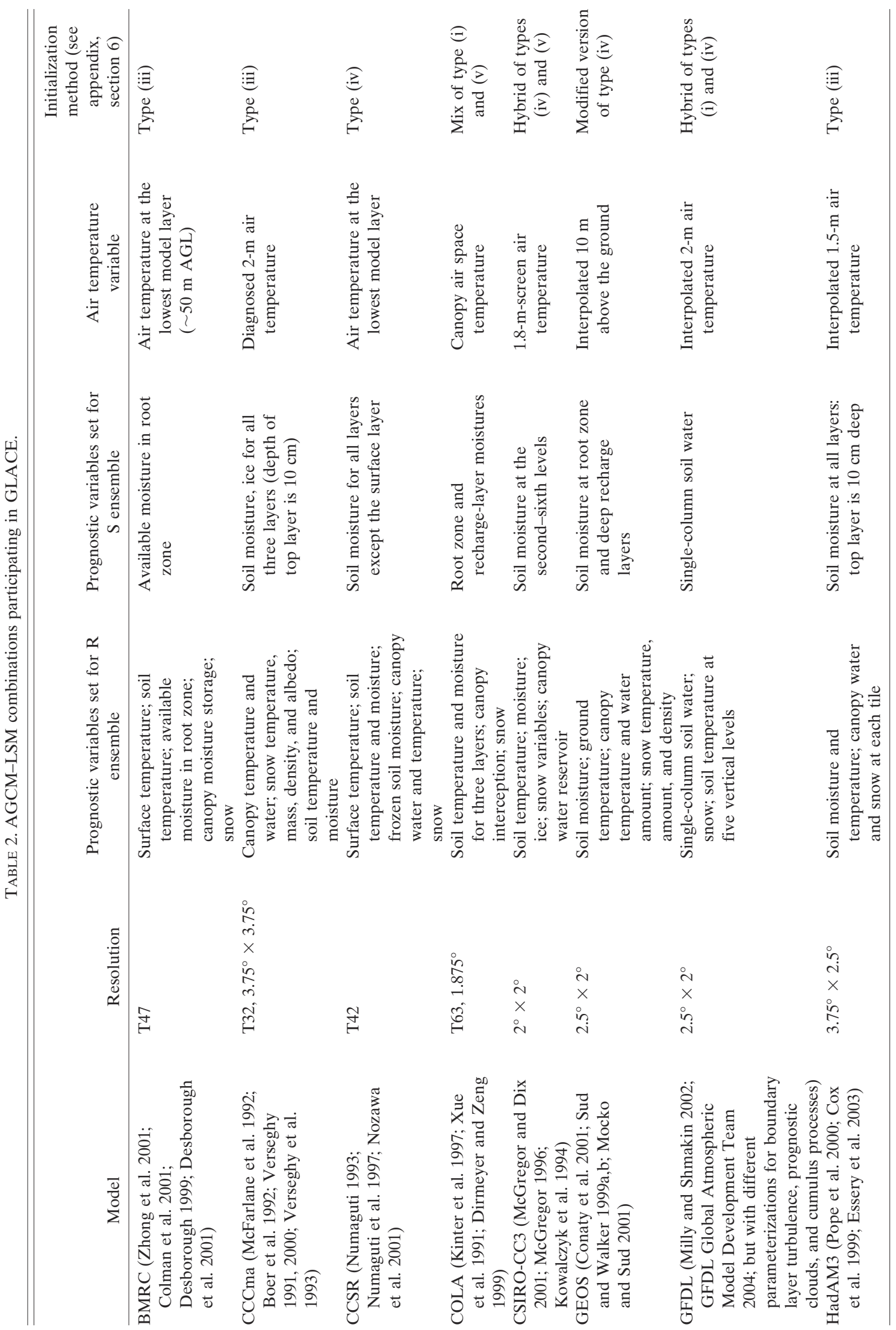




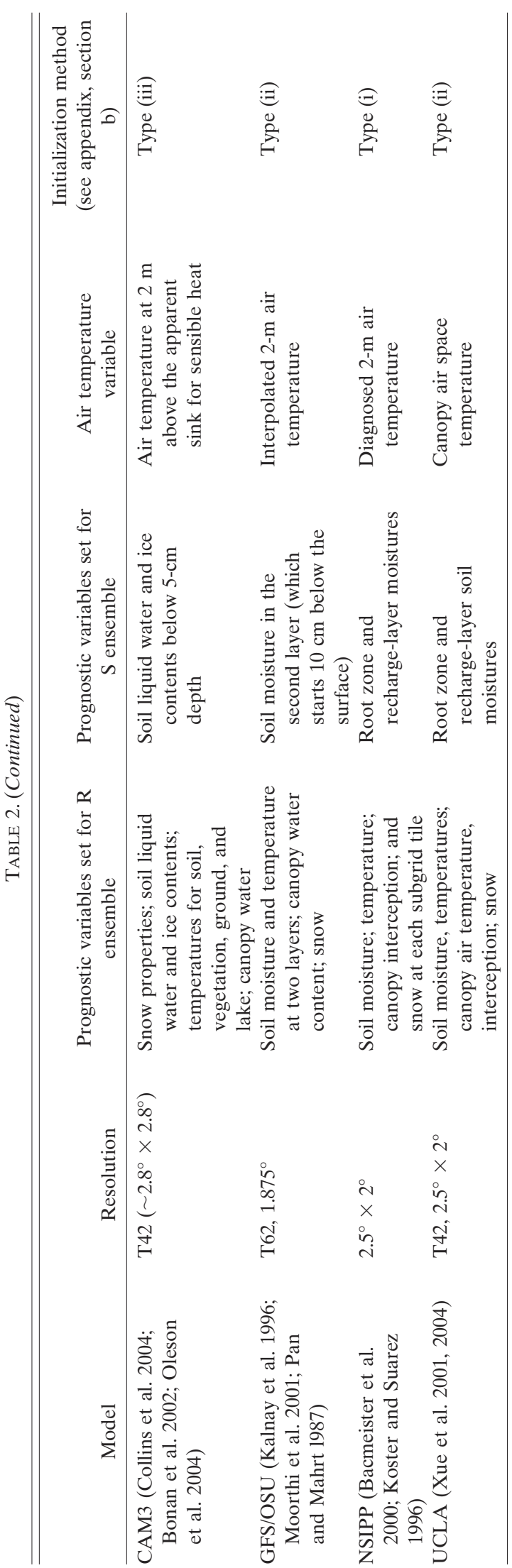

$$
\Omega_{P}=\frac{16 \sigma_{\hat{P}}^{2}-\sigma_{P}^{2}}{15 \sigma_{P}^{2}} .
$$

Here, $\Omega_{P}$ measures the degree to which the 16 precipitation time series generated by the ensemble members are similar. Indeed, $\Omega_{P}$ measures the relative contributions of boundary forcing and internal chaotic variability to the generation of precipitation (T. Yamada et al. 2006, unpublished manuscript). Consider the precipitation anomaly time series (normalized by standard deviation) for ensemble member $i$ written in the form

$$
P_{i}(t)=\rho B(t)+\left(1-\rho^{2}\right)^{1 / 2} \zeta_{i}(t),
$$

where $B(t)$ is the "boundary forced" contribution to the anomaly, which is the same for all ensemble members, and $\zeta_{i}(t)$ is the random component, which varies with ensemble member (and in fact makes them distinct). Here, both $B(t)$ and $\zeta_{i}(t)$, like $P_{i}(\mathrm{t})$, are expressed as standard normal deviates, that is, the variables have a mean of zero and a standard deviation of 1 . Under this representation, $\rho^{2}$ and $\Omega_{P}$ can be shown to be mathematically equivalent. Stated another way, $\Omega_{P}$ is equivalent to the ratio of the explained precipitation variance to total precipitation variance. It varies from (approximately) 0 to 1 , with higher values implying a greater contribution of boundary and initial conditions (and thus a lesser contribution of atmospheric chaos) to the evolution of precipitation in a given AGCM. Notice that if all simulations produced precisely the same precipitation time series, implying no chaotic contribution, $\sigma_{\hat{P}}$ would be identical to $\sigma_{P}$, and $\Omega_{P}$ would be exactly one. K02 provides a graphic interpretation of the meaning of the $\Omega_{P}$ diagnostic (see Fig. 2 of K02).

In Part II of this study, we assume that the boundary effects of land moisture on precipitation are mostly local, an assumption that proves very effective for understanding the intermodel differences in coupling strength. Note, however, that the definition of $\Omega_{P}$ does not by itself discriminate between local and remote boundary influences. The variable $B(t)$ in (3) could, for example, be determined entirely from land moisture conditions far upstream of the precipitation generation. In examining the maps of $\Omega_{P}$ in the present paper, one need not implicitly assume a "local influence."

Figure 2 shows the global fields of $\Omega_{P}(W)$ (i.e., $\Omega$ from the $\mathrm{W}$ ensemble) for all $12 \mathrm{AGCM}$-land surface model (LSM) combinations. Land states are not prescribed in ensemble $\mathrm{W}$; thus, $\Omega_{P}(W)$ reflects the extent to which low-frequency seasonal variations, as induced by the time variations of imposed boundary conditions and forcing alone (e.g., SST, vegetation structure, and 
$\Omega_{\mathrm{p}}(W)$
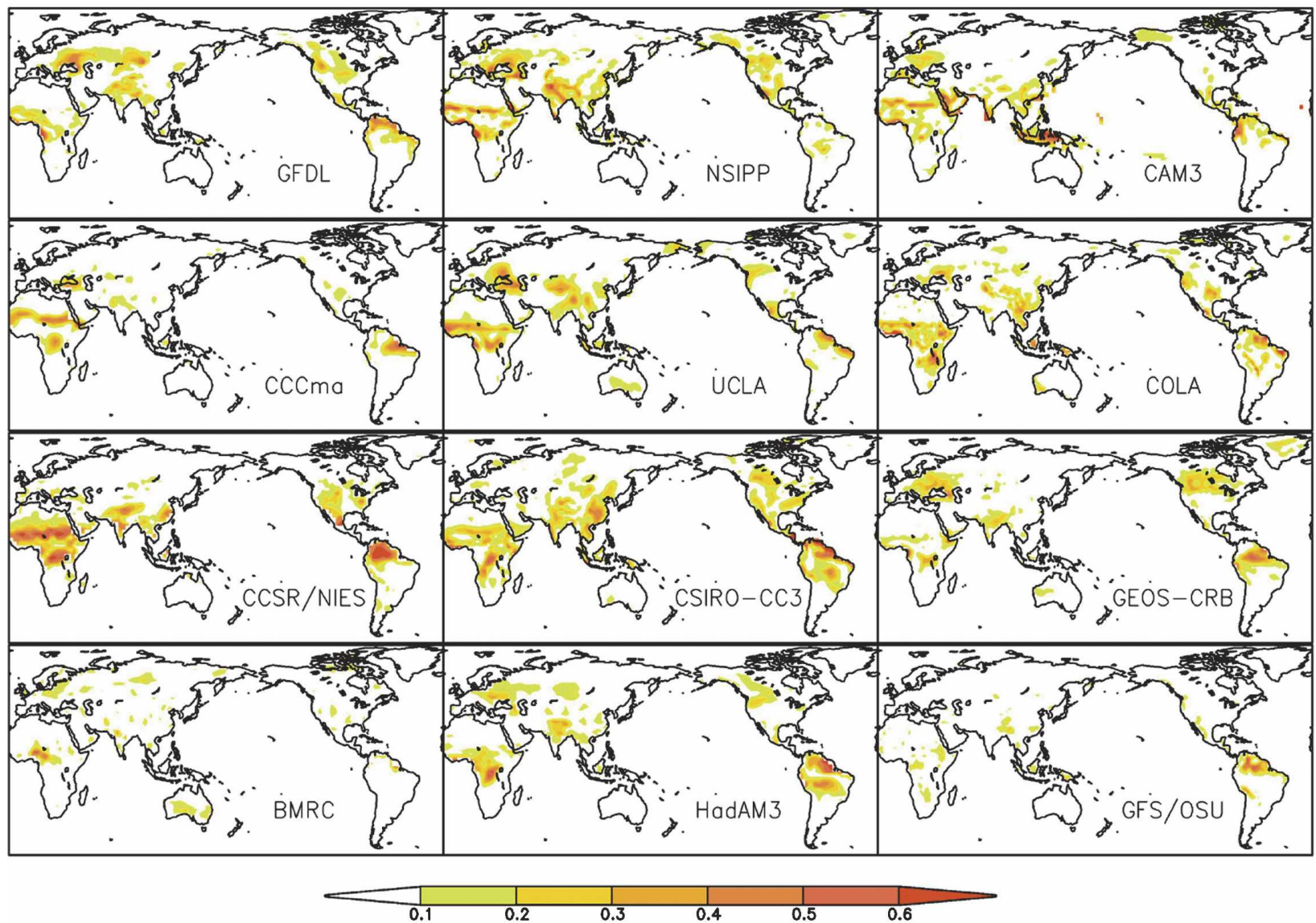

FIG. 2. Global distributions of $\Omega_{P}(W)$ for the models participating in GLACE.

solar declination), lead to strong similarity in the precipitation rates. (Note that while this similarity may be strengthened in ensemble $\mathrm{W}$ through land-atmosphere feedback, the ultimate source of the similarity lies in the prescribed boundary conditions and forcing.) The high values of $\Omega_{P}(W)$ tend to be clustered in the Tropics (where the ITCZ is migrating) and in a few midlatitude regions, such as eastern and southern Europe. An example of a model's behavior at a grid cell with high $\Omega_{P}(W)$ is shown in Fig. 3. Plotted in the figure are 16 time series of precipitation, one for each of the ensemble W simulations produced by CCSR/NIES over a grid cell in equatorial Africa. The same strong seasonality pervades each ensemble member, leading to a high synoptic-scale precipitation similarity over the duration of the simulation and thus to a high value (0.59) of $\Omega_{P}(W)$.

To quantify land-atmosphere coupling strength, we note that in ensemble $\mathrm{R}$, the explained variance-the similarity of precipitation between the ensemble members-has the following two distinct sources: (a) the prescribed land variables and (b) the background seasonal behavior that contributes to $\Omega_{P}(W)$, as exemplified in Fig. 3. Thus, subtracting $\Omega_{P}$ for ensemble $\mathrm{W}$ from that for ensemble $\mathrm{R}$ should isolate the impact of prescribed land variables on the synoptic-scale precipitation variance. We use the difference in similarity $\Omega_{P}(R)-\Omega_{P}(W)$ to measure land-atmosphere coupling strength associated with the prescription of all land

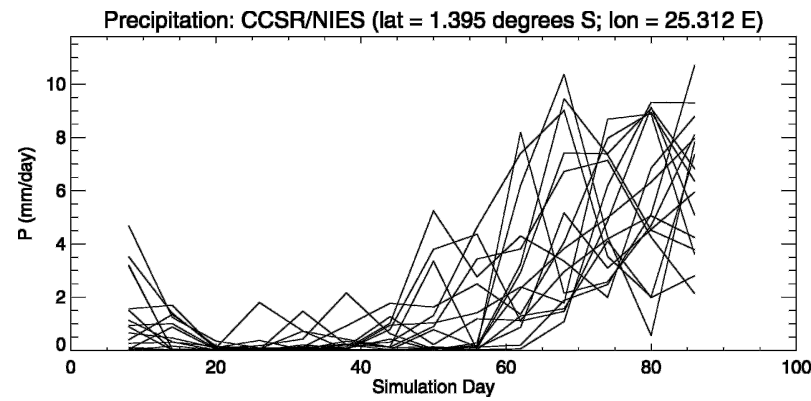

FIG. 3. Time series of rainfall (one line for each ensemble member) at a grid cell with a high $\Omega_{P}(W)$. 


$$
\Omega_{\mathrm{P}}(R)-\Omega_{\mathrm{P}}(W)
$$

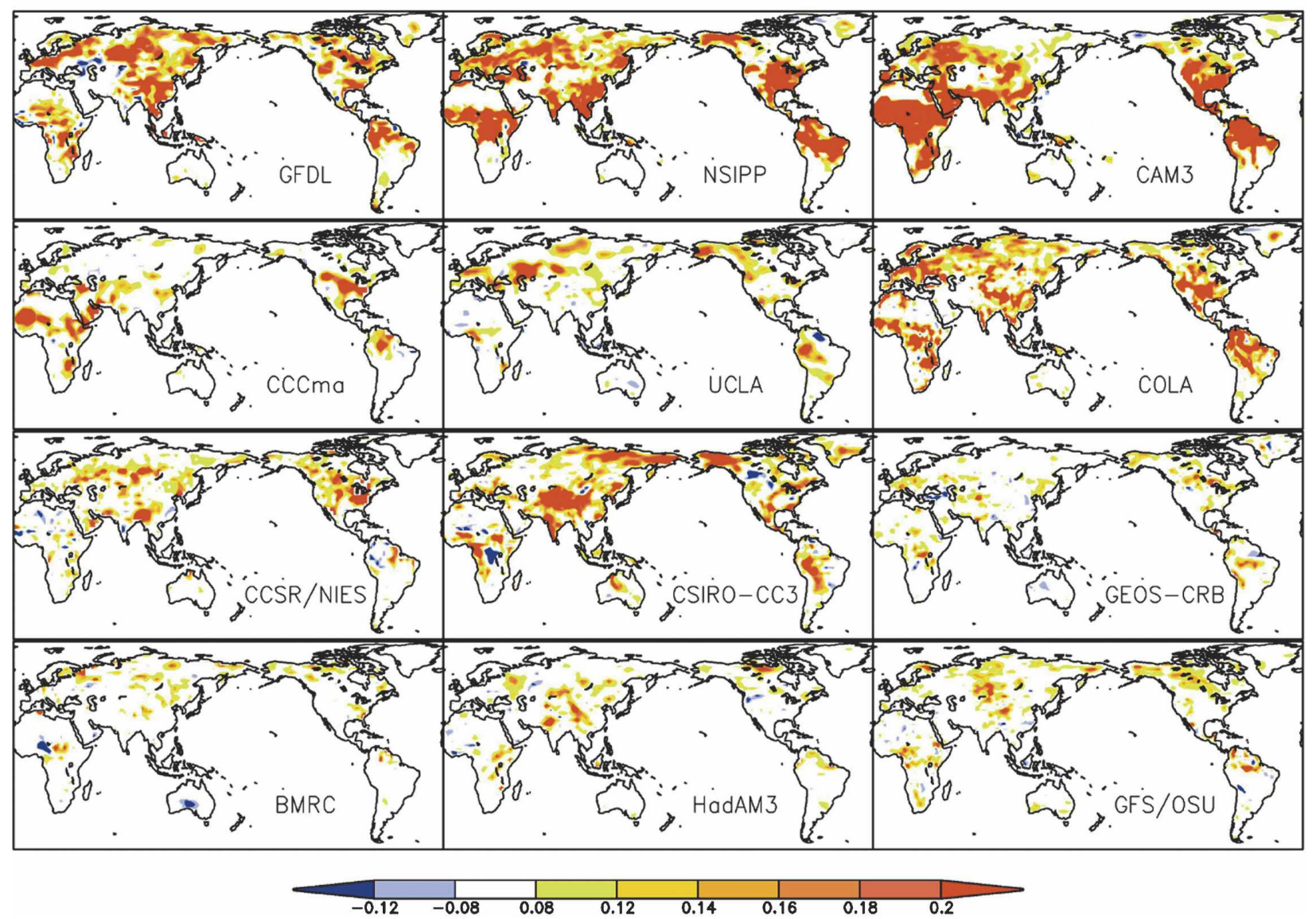

FIG. 4. Global distributions of $\Omega_{P}(R)-\Omega_{P}(W)$ for the models participating in GLACE.

variables. At a single grid cell, an $\Omega$ difference of 0.06 is significant at the $95 \%$ confidence level.

Of course, if $\Omega_{P}(W)$ is already close to 1 because of the background annual cycle of the imposed boundary conditions and forcing, the impact of land conditions, as represented by the difference, will necessarily appear small, regardless of its true value. This is not a major issue, however; the maximum of $\Omega_{P}(W)$ across the different models over nonice land points lies below 0.8 , and as seen in Fig. 2, $\Omega_{P}(W)$ generally falls very far below this maximum for the 92-day period considered.

Figure 4 shows the global fields of $\Omega_{P}(R)-\Omega_{P}(W)$ for all 12 AGCM-LSM combinations. This figure is, in effect, a more comprehensive version of Fig. 3 in K02. As in that earlier figure, Fig. 4 shows a wide intermodel disparity in the degree to which the atmosphere responds to the imposed land surface anomalies. Some models have relatively high values of $\Omega_{P}(R)-\Omega_{P}(W)$ (e.g., GFDL, NSIPP, CAM3, COLA, CSIRO), and others show relatively low values (e.g., HadAM3, BMRC, GFS/OSU, GEOS-CRB). Generally, however, $\Omega_{P}(R)$
- $\Omega_{P}(W)$ is small in Southern Hemisphere midlatitudes and in deserts, presumably because the low mean evaporation rates imply little variability in the surface energy balance. The low evaporation rates in the Southern Hemisphere reflect wintertime conditions; a repeat of the experiments for austral summer could prove useful.

While the patterns and magnitudes shown in Fig. 4 are intriguing, they may be of largely academic interest, because they may be controlled mostly by "fast" land surface prognostic variables, which have little temporal memory and cannot be used for long-term prediction. In contrast, ensemble $S$ focuses on the "slow" subsurface moisture variables that can contribute to prediction. Figure 5 shows the global fields of $\Omega_{P}(S)-$ $\Omega_{P}(W)$ for all 12 AGCM-LSM combinations. In analogy to $\Omega_{P}(R)-\Omega_{P}(W), \Omega_{P}(S)-\Omega_{P}(W)$ isolates the contribution of prescribed subsurface soil moisture to precipitation variability, that is, to the evolution of precipitation on synoptic time scales.

As in the comparisons of $\Omega_{P}(R)-\Omega_{P}(W)$, a strong 


$$
\Omega_{\mathrm{P}}(S)-\Omega_{\mathrm{P}}(W)
$$
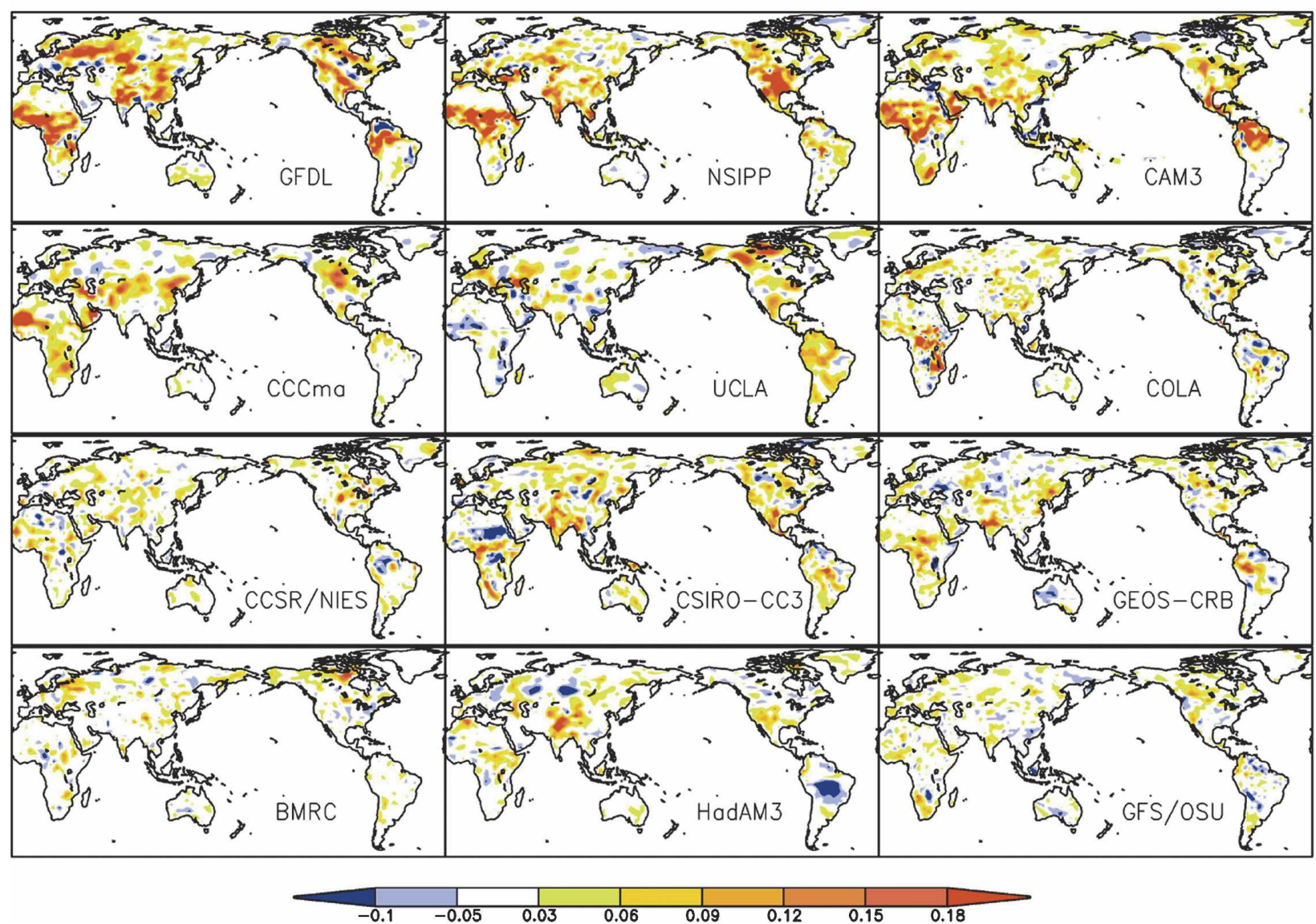

FIG. 5. Global distributions of $\Omega_{P}(S)-\Omega_{P}(W)$ for the models participating in GLACE.

diversity of coupling strength is seen among the AGCMs. Some models (e.g., GFDL, CAM3, NSIPP, CCCma) have a distinct large-scale structure associated with their $\Omega_{P}(S)-\Omega_{P}(W)$ values; large patches of relatively high $\Omega_{P}(S)-\Omega_{P}(W)$ can be seen, for example, in central North America and the Sahel. Other models (e.g., CCSR/NIES, HadAM3, BMRC, GFS/OSU) have relatively few such structures; for the most part, small values of $\Omega_{P}(S)-\Omega_{P}(W)$ are scattered randomly across the globe. Note that a certain amount of agreement is seen in the positioning of the $\Omega_{P}(S)-\Omega_{P}(W)$ structures that do appear. This will be discussed further in section 5 .

Most models even show some negative values of $\Omega_{P}(S)-\Omega_{P}(W)$. The reasons are unclear, but the highly infrequent negative values may have occurred by chance; according to Monte Carlo analysis, under an assumption of independent rainfall amounts in consecutive 6-day periods, a difference of either -0.1 or 0.1 is statistically significant at the $99.6 \%$ level, so a false negative may occur in about $0.4 \%$ of the grid cells plot- ted. Differences of -0.05 and 0.05 are statistically significant at the $92 \%$ level. (Relaxing the assumption of independence makes the occurrence of spurious negative values slightly more likely.) Note that for the $\Omega_{P}(R)-\Omega_{P}(W)$ field, negative values may have a different source; the specification of land states may have led to artificially large vertical gradients between the land surface and the free-running atmosphere, causing instabilities and unrealistic fluxes in the integrations and thus abnormal model behavior (Reale et al. 2002).

The highest values of $\Omega_{P}(S)-\Omega_{P}(W)$ in Fig. 5 are of the order of 0.2 , implying that soil moisture variability explains about $20 \%$ of the synoptic-scale precipitation variability (see section 4a). Interestingly, various estimates of precipitation recycling (Brubaker et al. 1993; Elfatih and Bras 1996; Trenberth 1999) suggest that, for many regions, about $25 \%$ of the precipitation is derived from local evaporation. Such recycling estimates cannot be used to validate $\Omega_{P}(S)-\Omega_{P}(W)$ values for the following several reasons: (a) through the triggering of convection and other processes, the land surface can 
influence rainfall by influencing the advection of external moisture into a region, and the rainout of this external moisture is reflected in $\Omega_{P}(S)-\Omega_{P}(W)$, but not in the recycling ratio; (b) a 100\% recycling ratio, if one could exist, would not necessarily imply a high $\Omega_{P}(S)-$ $\Omega_{P}(W)$ value, because intraensemble evaporation rates (and thus rainfall rates) could still vary because of intraensemble differences in atmospheric moisture demand; (c) relative to $\Omega_{P}(S)-\Omega_{P}(W)$, recycling ratios are independent of time scale; (d) on the other hand, recycling ratios are strongly dependent on the specified spatial scale, whereas $\Omega_{P}(S)-\Omega_{P}(W)$ is not (it reflects the influence of the entire land boundary); and (e) recycling ratios are not "observed" themselves; the published rates reflect critical assumptions regarding atmospheric mixing and upstream evaporation rates. Still, both the low $\Omega_{P}(S)-\Omega_{P}(W)$ values and the low recycling ratio estimates consistently suggest that the land's impact on rainfall is relatively subtle-significant in places, but still small relative to the effects of other influences (such as internal atmospheric variability).

For ease of comparison, Fig. 6 shows the values of $\Omega_{P}(W), \Omega_{P}(R)-\Omega_{P}(W)$, and $\Omega_{P}(S)-\Omega_{P}(W)$ for each model, averaged across all nonice land points. Note the different scale for Fig. 6c; the specification of subsurface soil moisture has a much smaller impact on precipitation's synoptic-scale variability than does either the background seasonality (Fig. 6a) or the specification of fast variables (Fig. 6b). Though the numbers for $\Omega_{P}(S)-\Omega_{P}(W)$ appear especially small, we must keep in mind that the global averaging will hide any of the larger $\Omega_{P}(S)-\Omega_{P}(W)$ values that appear regionally. In certain regions, subsurface soil moisture can have a significant impact on rainfall, and can thus be useful for seasonal prediction, even if the globally averaged impact appears quite small.

The model diversity seen in the histograms reflects that seen in the maps. On a global average basis, the coupling strength associated with all land variables [Fig. $6 \mathrm{~b}$, showing $\left.\Omega_{P}(R)-\Omega_{P}(W)\right]$ is more than 4 times higher in some models (e.g., CAM3, NSIPP) than it is in some other models (e.g., BMRC, HadAM3, GEOSCRB). The impact of subsurface soil moisture on the evolution of precipitation (Fig. 6c) is just as model dependent; the more strongly coupled models (GFDL, CAM3, NSIPP, CCCma) stand out distinctly from the more weakly coupled models (HadAM3, BMRC, GFS/ OSU).

Recall that $\Omega$ can be interpreted as the fraction of the total variance that is "explained" by the imposed boundary conditions. The bottom panel in Fig. 6 shows, for reference, the total variance of 6-day precipitation totals for ensemble $\mathrm{W}\left[\sigma_{P}^{2}(W)\right]$, averaged across land points. Some interesting features are seen. For example, the GEOS-CRB model has the highest background variance, suggesting that this model's low $\Omega_{P}(R)-\Omega_{P}(W)$ and $\Omega_{P}(S)-\Omega_{P}(W)$ may stem in part from the difficulty of diminishing this larger variance. On the other hand, CAM3 and NSIPP show lower values of $\sigma_{P}^{2}(W)$ and higher values of $\Omega_{P}(R)-\Omega_{P}(W)$ and $\Omega_{P}(S)-\Omega_{P}(W)$. Overall, though, the models' values of $\sigma_{P}^{2}(W)$ are roughly similar and do not explain the intermodel differences in coupling strength. The similar $\sigma_{P}^{2}(W)$ for GFDL and GFS/OSU and for UCLA and CAM3, for example, do not lead to similar coupling strength behavior.

\section{b. Surface air temperature}

Figure 7 shows the global distribution of $\Omega_{T}(W)$ for the different models, and Fig. 8 shows the corresponding distributions of $\Omega_{T}(S)-\Omega_{T}(W)$. [The temperature analysis does not consider $\Omega_{T}(R)-\Omega_{T}(W)$, because temperatures in the $\mathrm{R}$ ensemble are overly influenced by the specified ground temperatures.] From Fig. 7, we see that in many regions, a significant amount of the temperature similarity between ensemble members reflects a background seasonal cycle controlled by external influences (SST, radiation). As a result, the fields of $\Omega_{T}(S)-\Omega_{T}(W)$ must be regarded with caution; $\Omega_{T}(S)-\Omega_{T}(W)$ may be an imperfect indicator of landatmosphere coupling in the regions where $\Omega_{T}(W)$ is especially large. For example, $\Omega_{T}(S)-\Omega_{T}(W)$ looks small for the Amazon for CSIRO. This small difference probably reflects a large $\Omega_{T}(W)$ value rather than a weak land-atmosphere coupling. In such regions, the small differences simply imply that our ability to discern land-atmosphere coupling from the coordination of air temperature time series across ensemble members is limited. [Again, this is not an issue for precipitation, because $\Omega_{P}(W)$ is generally small everywhere.]

With this caveat, we examine the global fields of $\Omega_{T}(S)-\Omega_{T}(W)$ in Fig. 8 and find a strong disparity in the control of subsurface soil moisture on the synopticscale variability of air temperature, with some models (e.g., GFDL, HadAM3, CCCma, CSIRO) showing a high degree of control and others (e.g., COLA, BMRC, GFS/OSU) showing a much more limited control. Also in analogy to the precipitation analysis, some regions of coupling (e.g., the Sahel, northeastern China, and south-central North America) tend to show up in many of the models.

Figure 9a shows the global average (over nonice land points) of $\Omega_{T}(W)$; again, the averages are much larger than those for $\Omega_{P}(W)$, presumably because of the strong background seasonal temperature cycle within 
(a) Average of $\Omega_{\mathrm{p}}(\mathrm{W})$ :

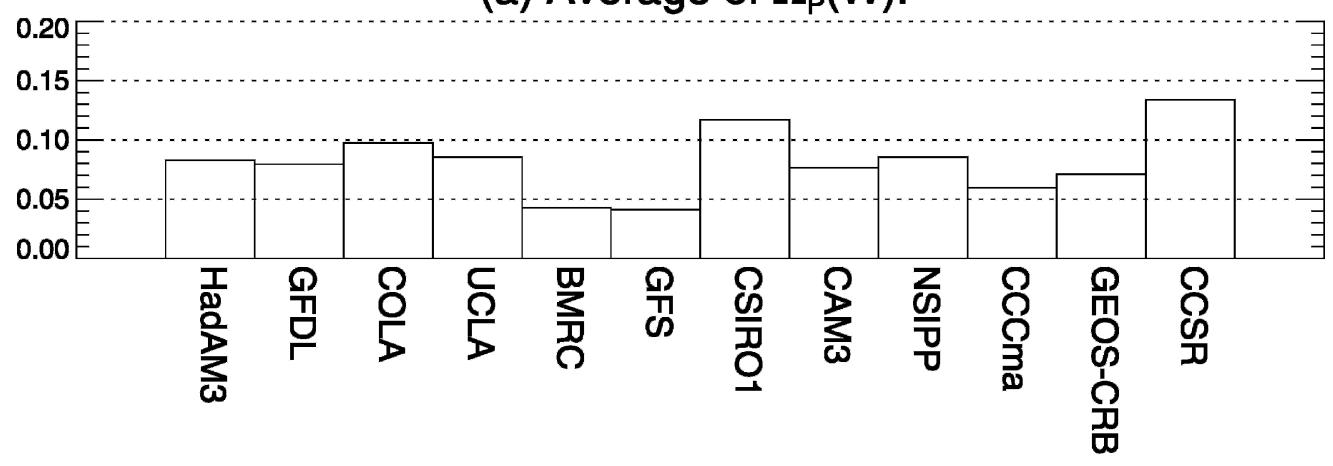

(b) Average of $\Omega_{\mathrm{p}}(\mathrm{R})$ minus $\Omega_{\mathrm{P}}(\mathrm{W})$ :

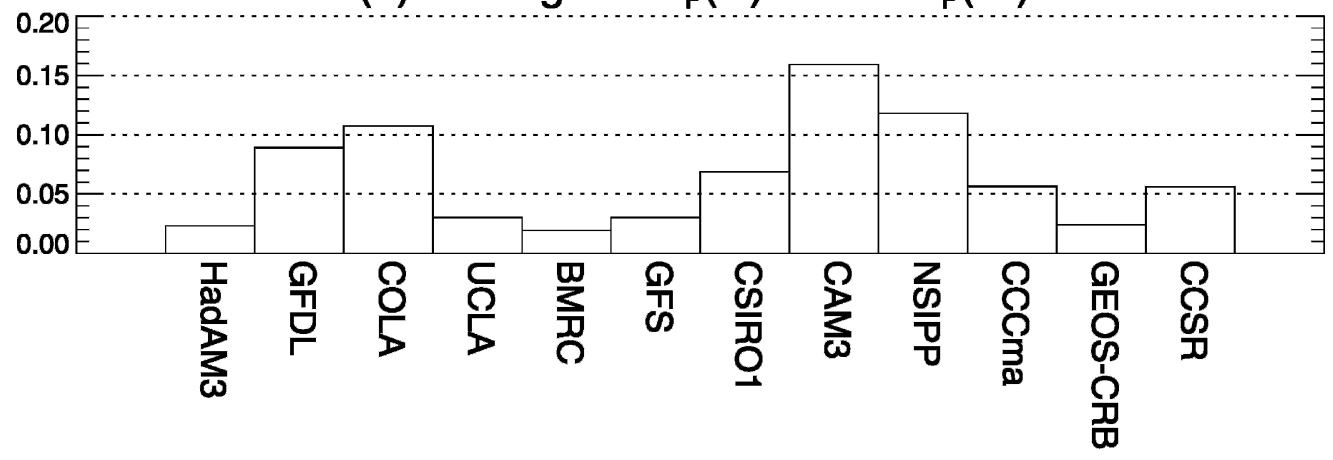

(c) Average of $\Omega_{\mathrm{P}}(\mathrm{S})$ minus $\Omega_{\mathrm{P}}(\mathrm{W})$ :

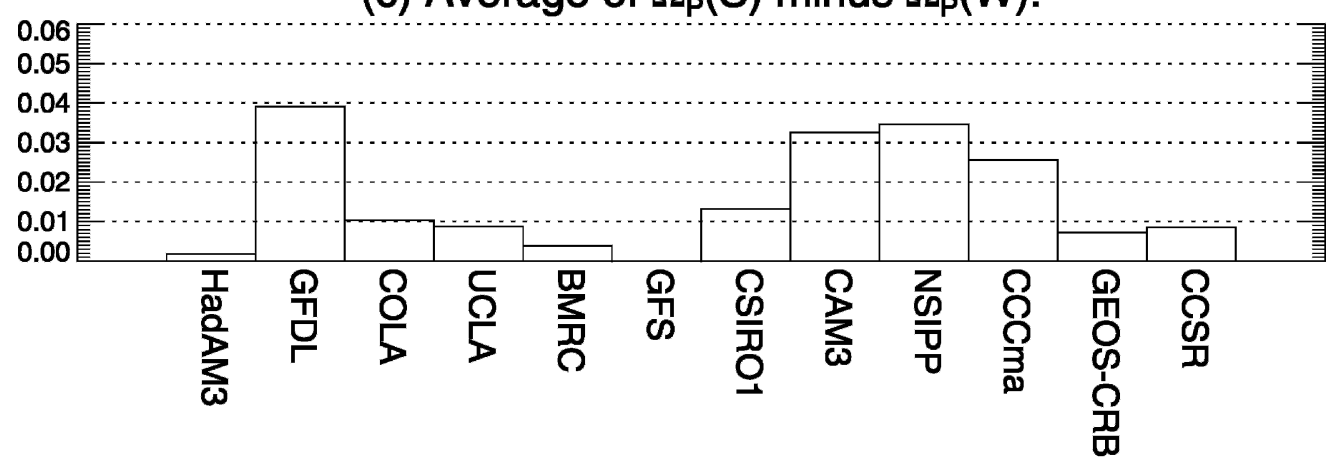

(d) Average of $\sigma_{p}^{2}(W)$ :

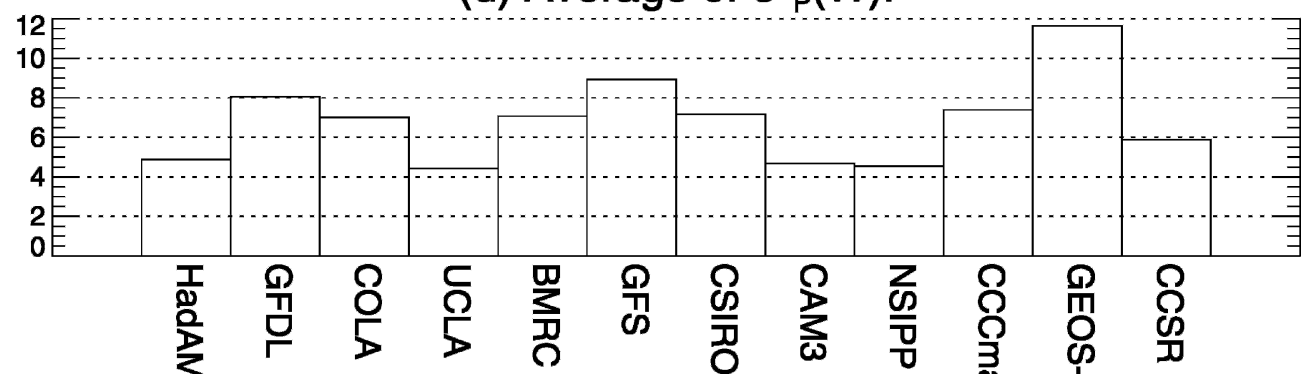

FIG. 6. (a) Mean of $\Omega_{P}(W)$ across nonice land grid cells for the models participating in GLACE. (b) Same as (a), but for $\Omega_{P}(R)-\Omega_{P}(W)$. (c) Same as (a), but for $\Omega_{P}(S)-\Omega_{P}(W)$. (d) Same as (a), but for $\sigma^{2}(W)$. 
$\Omega_{\mathrm{T}}(\mathrm{W})$
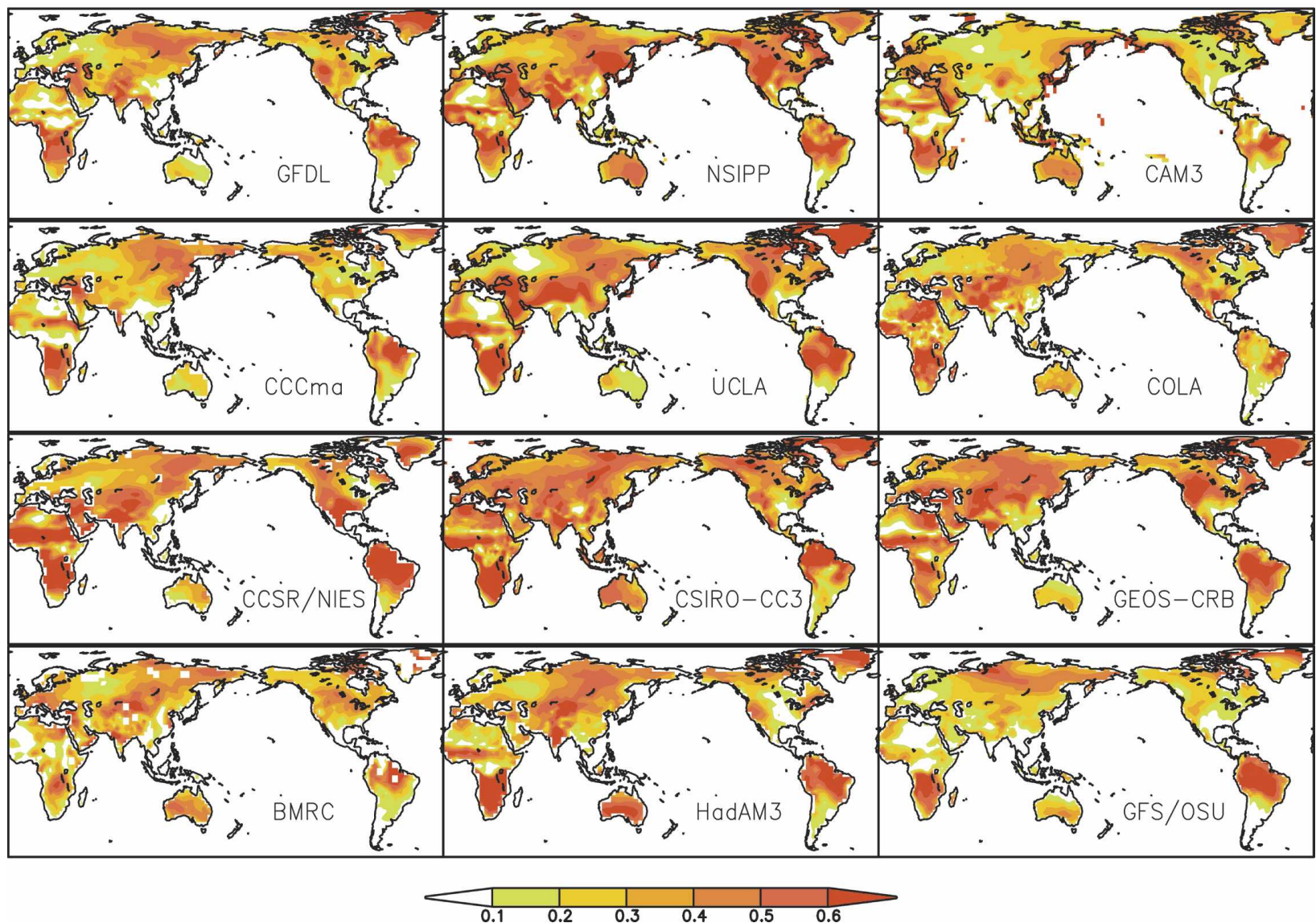

FIG. 7. Global distributions of $\Omega_{T}(W)$ for the models participating in GLACE.

each model. Figure $9 \mathrm{~b}$ shows the average of $\Omega_{T}(S)-$ $\Omega_{T}(W)$ across nonice land squares for each model. Comparing this figure with Fig. 6c reveals two important things. First and foremost, the land's control on air temperature is generally much larger than its control over precipitation. This is not surprising given that evaporation, through latent cooling and the associated impact on sensible heat flux, has a stronger connection to near-surface temperature than to precipitation, which is produced at higher atmospheric levels, and thus depends in part on convection and boundary layer formulations. (This is addressed in more detail in Part II.) Second, a low control on precipitation relative to other models does not imply a relatively low control on air temperature as well. HadAM3, for example, has a reasonably high average $\Omega_{T}(S)-\Omega_{T}(W)$ value, despite its low average value of $\Omega_{P}(S)-\Omega_{P}(W)$. Figure 9c shows the global average of air temperature variance over land points for ensemble $\mathrm{W}\left[\sigma_{T}^{2}(W)\right]$; a higher background temperature variance does not correlate with a lower coupling strength.

\section{5. "Hot spots" of land-atmosphere coupling}

Figure 5 does suggest some systematic regional variations in precipitation's response to soil moisture. Several models, for example, place relatively high values of $\Omega_{P}(S)-\Omega_{P}(W)$ in the Sahel and central North America. Some intermodel similarity is also seen in the $\Omega_{T}(S)-\Omega_{T}(W)$ fields. GLACE has a noteworthy strength-it provides a unique chance to quantify multimodel "agreement" in the locations of the land moisture impact on the atmosphere. It can provide a more robust estimate of where the coupling is relatively strong, an estimate that is less subject to the specific process formulations of any one particular model.

This strength of GLACE motivated a recent paper (Koster et al. 2004) highlighting these "hot spots" for precipitation, that is, identifying the areas in which, for many of the models, the land-atmosphere coupling strength is relatively large. Plotted in that paper was the global field of $\Omega_{P}(S)-\Omega_{P}(W)$, averaged across all participating models. A slightly different version of the 


$$
\Omega_{\mathrm{T}}(S)-\Omega_{\mathrm{T}}(W)
$$

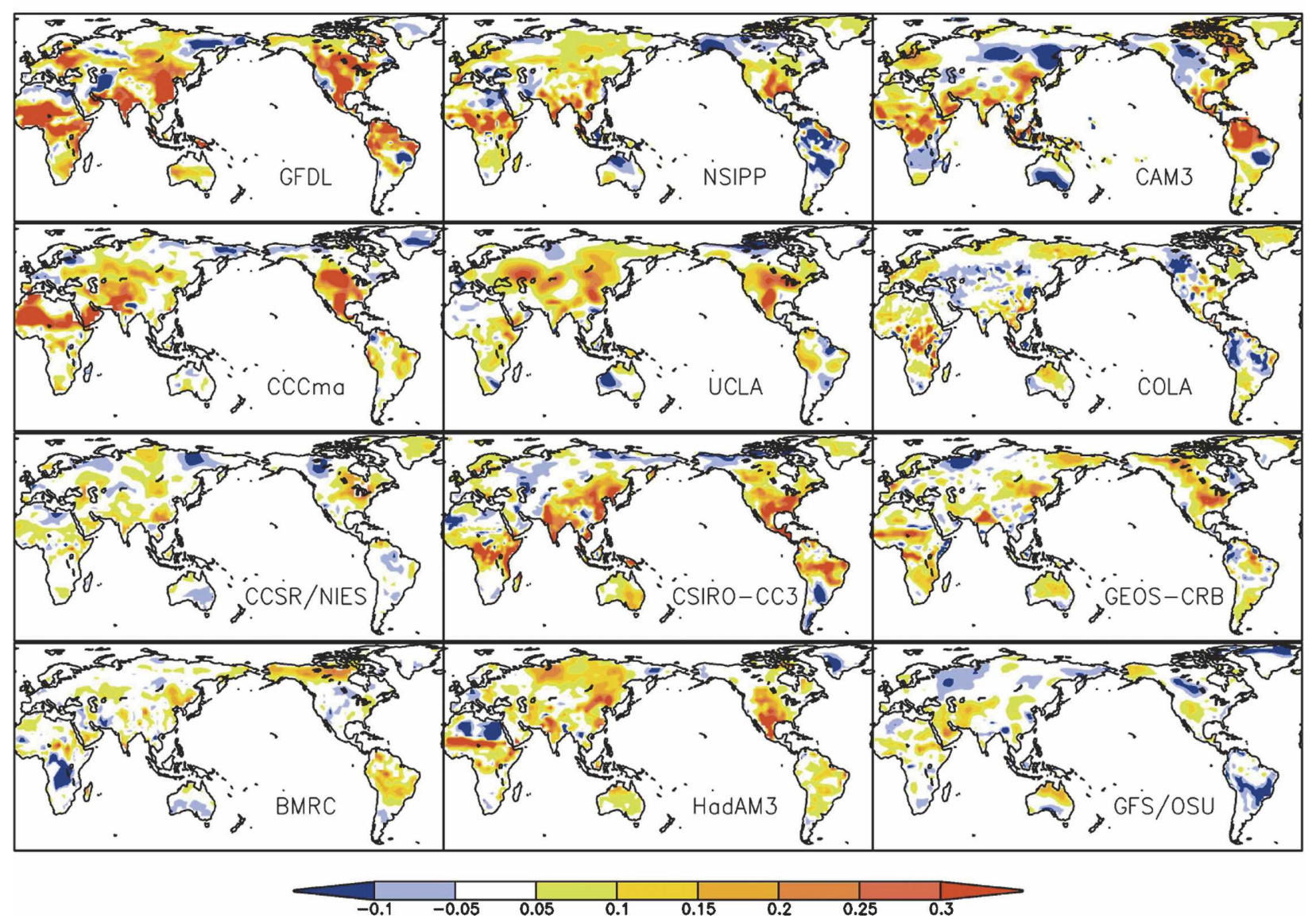

FIG. 8. Global distributions of $\Omega_{T}(S)-\Omega_{T}(W)$ for the models participating in GLACE.

plot is shown in the top panel of Fig. 10; the version is different because here, to maintain consistency with the rest of our two-part paper, statistics are computed on the precipitation values themselves rather than on their natural logarithms. (Although performing statistics on the natural logarithms of precipitation is a common and useful practice in hydrology and meteorology, because it reduces noise associated with high rainfall amounts, it produces technical problems for some of our analyses.) To produce the plot, the results from each model were disaggregated to the same very fine grid-one with a resolution of $0.5^{\circ} \times 0.5^{\circ}$. Disaggregation was performed in the simplest way possible. Each $0.5^{\circ} \times 0.5^{\circ}$ grid cell lies wholly or mostly within a coarse grid cell of a given model. The precipitation rate assigned to the fine grid cell was that which applies to the coarse grid cell containing it.

The top panel of Fig. 10 shows that hot spots appear in the central Great Plains of North America, northern India, the Sahel, equatorial Africa, and a few additional regions. Because the logarithms of rainfall amounts are not used, however, the magnitudes of the plotted coupling strengths are slightly reduced relative to those in Koster et al. (2004).

Note that a strict arithmetical average across the 12 models was used to generate the figure. An alternative approach would be to give added weight to the models with more realistic climate. The bottom panel of the figure shows the results of one such weighted calculation. In the approach used here, the $\Omega_{P}(S)-\Omega_{P}(W)$ values are averaged across only the eight models that, at a given grid cell, best reproduce the observed climatological average precipitation for June through August [from the Global Precipitation Climatology Project (GPCP); Huffman et al. 1997]. Thus, a different set of eight models may contribute to the plotted average at adjacent locations. This approach is limited in scope; indeed, all possible weighting approaches are necessarily imperfect. The two chief deficiencies of the weighting applied here are that (i) rainfall rates used to evaluate the "realism" of a model may reflect the year chosen for the SST boundary condition, whereas the 
(a) Average of $\Omega_{\mathrm{T}}(\mathrm{W})$ :

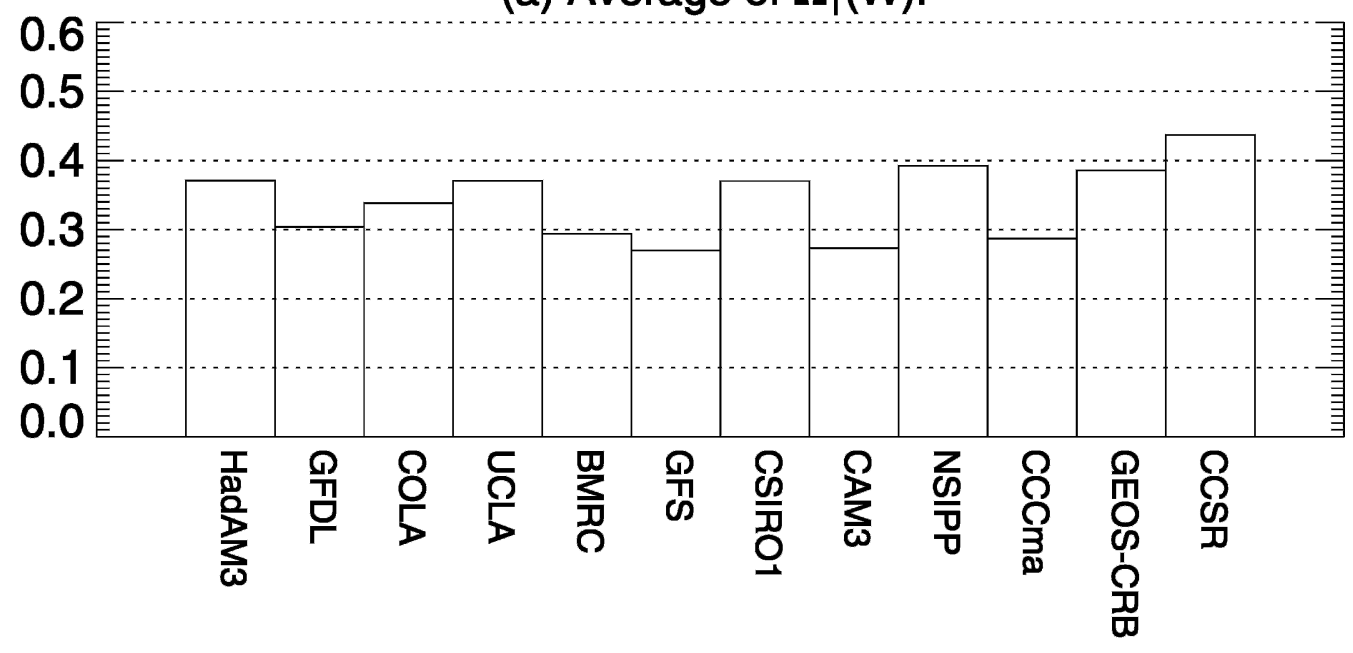

(b) Average of $\Omega_{\mathrm{T}}(\mathrm{S})$ minus $\Omega_{\mathrm{T}}(\mathrm{W})$ :

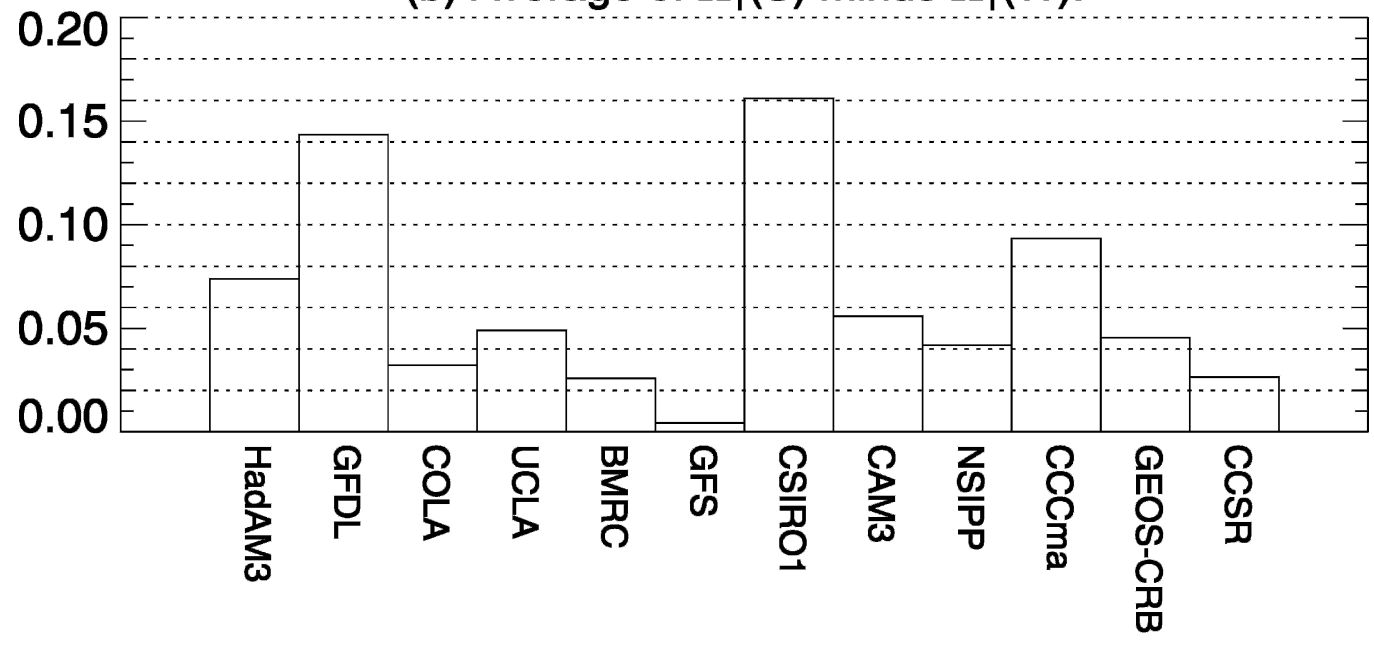

(c) Average of $\sigma_{T}^{2}(W)$ :

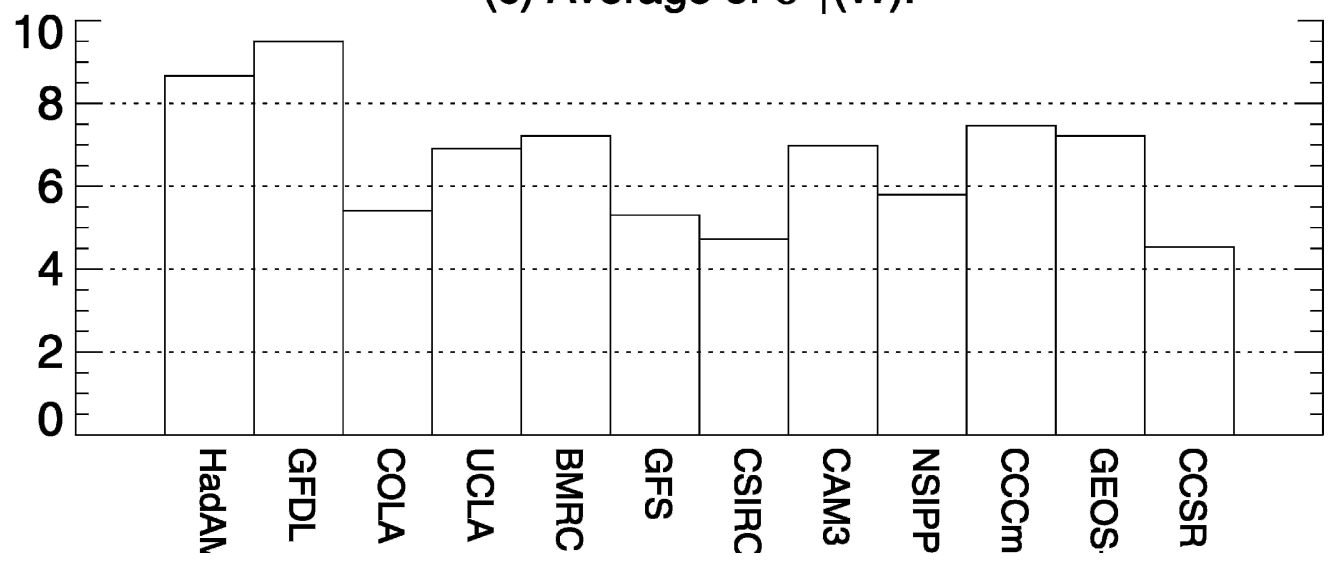

FIG. 9. (a) $\Omega_{T}(W)$ for the models participating in GLACE, averaged over nonice land points. (b) Same as (a), but for $\Omega_{T}(S)-\Omega_{T}(W)$. (c) Same as (a), but for $\sigma_{T}^{2}(W)$. 

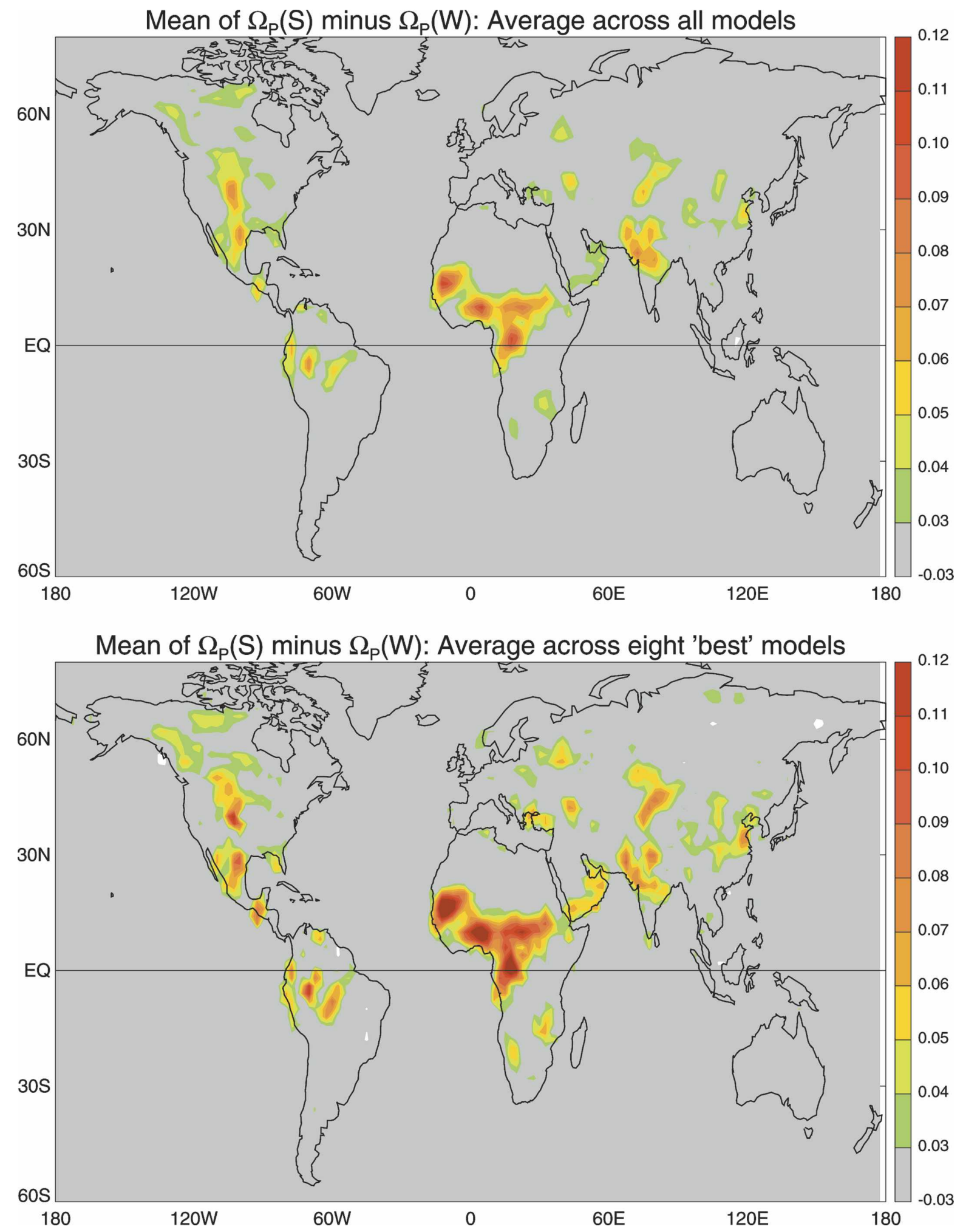

FIG. 10. (top) Average of $\Omega_{P}(S)-\Omega_{P}(W)$ across all 12 models and (bottom) average of $\Omega_{P}(S)-\Omega_{P}(W)$ across the 8 models that, at a given grid cell, reproduce most closely the observed mean June-August (JJA) precipitation. 
climatological average for observations represents a mean over many years, and (ii) a model may have a realistic mean climatology but poor variability characteristics, and vice versa. Nevertheless, the results of the exercise are illuminating. While the positions of the hot spots are similar to those in the top panel, the magnitudes of the averages have, in general, increased. In other words, by focusing on the models that appear to be more realistic in terms of precipitation climatology, we have increased the derived average coupling strength.

The equivalent two maps for air temperature are plotted in Fig. 11. The top panel shows $\Omega_{T}(S)-\Omega_{T}(W)$ averaged over all the models, and the bottom panel shows the "weighted average" result, again an eightmodel average based on the realism of simulated precipitation. The results from both maps suggest strong synoptic-scale coupling for temperature in the Sahel, the central Great Plains of North America, India, and (in contrast to precipitation) eastern Asia. Notice that the average coupling strength is significantly larger than that for precipitation.

Again, direct estimates of coupling strength from observations do not exist. Even if perfect measurements of precipitation and evaporation in a region were attainable, isolating evaporation's impact on rainfall in the presence of the more dominant impact of rainfall on evaporation would prove to be problematic. Observational estimates of land-atmosphere coupling are thus indirect at best (e.g., Koster et al. 2003; Koster and Suarez 2004). Although coupling strength in models can be precisely computed, the results from any one model may simply reflect the peculiarities of that model. Therefore, the multimodel averaging procedure applied here, though subject to deficiencies shared by multiple models, and though unable to generate quantitative estimates of reliability, still provides what is probably the best estimate possible for land-atmosphere coupling strength given the absence of direct observational data.

\section{Summary}

In nature, rainfall certainly affects soil moisture, and soil moisture may affect rainfall. As part of the GLACE project, a number of AGCM groups have performed a numerical experiment designed to isolate the latter direction of causality. Through GLACE, we quantify the impact of land conditions on the evolution of precipitation and temperature in boreal summer in each of the models, and we compare in detail the differences in this "coupling strength" between the models.
This paper has two main functions: (i) it describes GLACE with enough detail to allow for its execution in the future by any modeling group, and (ii) it documents the range of coupling strengths implicit now in the participating models, so that any future group can put their results immediately into context. The range of coupling strengths uncovered by GLACE is indeed large, as indicated by Figs. 4-9. We emphasize again that this intermodel disparity is not a trivial result, because coupling strength is not an explicitly defined quantity in the AGCMs; it is rather a complex product of many interacting model parameterizations. Most modelers have little notion of the degree of the land-atmosphere coupling implicit in their models. GLACE provides, for the first time, an objective methodology for its computation. Being able to compare a given model's coupling strength to that of other models is critical for interpreting, for example, land use impact experiments or precipitation forecasts based on soil water initialization.

A side benefit of GLACE is the determination of multimodel "hot spots" of land-atmosphere coupling, which are regions that, according to several AGCMs, have a relatively high coupling strength. Figure 10 shows, for example, that the Sahel and the Great Plains of the United States are hot spots of coupling for precipitation at synoptic time scales. The multimodel nature of this result gives it added validity; either several models are wrong in a similar way, or these are indeed regions of strong coupling in the real world.

Two questions naturally arise from this study. First, what causes the geographical variations in coupling strength seen for a given model in Figs. 5 and 8? Second, what causes the model-to-model differences in coupling strength, as summarized by the histogram plots? The answers certainly relate to differences in the parameterizations employed by the models and to differences in the simulated climates; some hydroclimatological regimes are presumably more amenable to coupling than others. Part II addresses these two questions in detail.

Acknowledgments. We thank Robert Dickinson and two anonymous reviewers for helpful comments, as well as the reviewers of the K02 paper for valuable suggestions on how to build on that earlier experiment. GLACE is a joint project of the Global Energy and Water Cycle Experiment (GEWEX) Global Land Atmosphere System Study (GLASS) panel and the Climate Variability Experiment (CLIVAR) Working Group on Seasonal-to-Interannual Prediction (WGSIP), all of which are under the auspices of the World Climate Research Programme (WCRP). The processing of the multimodel results was supported by National 


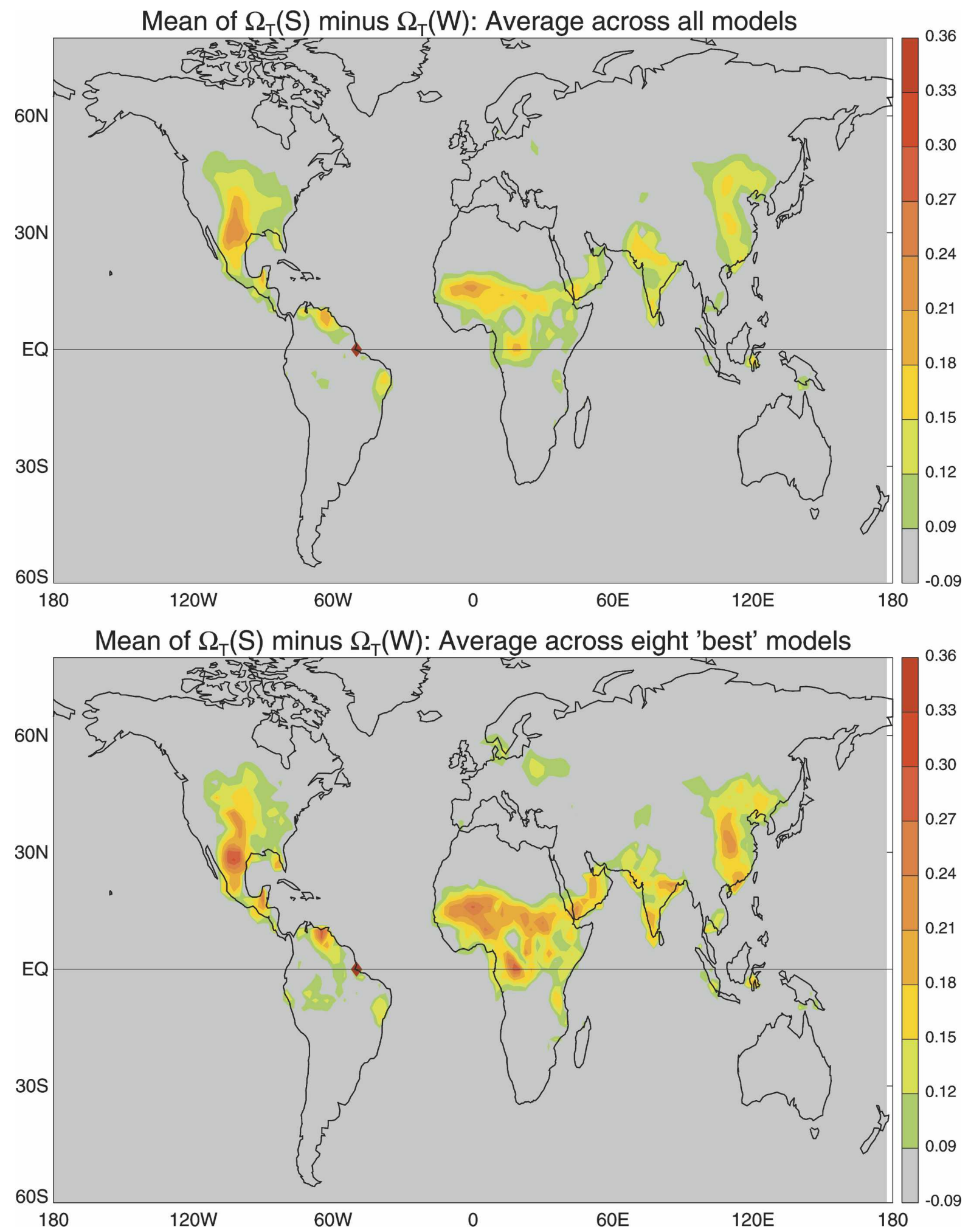

FIG. 11. (top) Average of $\Omega_{T}(S)-\Omega_{T}(W)$ across all 12 models and (bottom) average of $\Omega_{T}(S)-\Omega_{T}(W)$ across the 8 models that, at a given grid cell, reproduce most closely the observed mean JJA precipitation. 
Aeronautics and Space Administration Grant NAG511579. The individual contributions were supported by the participants' home institutions and funding agencies.

\section{APPENDIX A}

\section{Details of Experimental Design}

\section{a. Model-specific aspects of experiment}

The spatial resolution and the time step used necessarily varied among the participating AGCMs. Each group used a resolution that was typical for their model. Each group also applied their own strategy for writing out the prognostic variables in ensemble $\mathrm{W}$ and for reading them in ensembles $\mathrm{R}$ and $\mathrm{S}$.

\section{b. Initialization of ensemble members}

The members of an AGCM ensemble typically differ only in their initial atmospheric and land surface conditions. The approach for assigning the initial conditions is not strictly specified by GLACE; the only requirement is that the initial conditions be fully consistent with the AGCM being used. They are not allowed to be imported from some other model.

Several approaches for initializing land and atmosphere states are possible; they are listed in order of preference below [i.e., approach (i) is preferred most]. The key is to produce sets of initial conditions that sample the full range of possible land and atmosphere states. Initial land conditions between ensemble members, for example, should not be allowed to be artificially similar, as can happen through the commonly used approach (v).

(i) Some groups have an archived series of 16 or more parallel multidecade Atmospheric Model Intercomparison Project (AMIP)-type simulations available (i.e., simulations using SSTs prescribed from observations, as in AMIP) from which to extract 16 different sets of land and atmosphere states for 1 June 1994. These states can be used to initialize the $\mathrm{W}, \mathrm{R}$, and $\mathrm{S}$ ensembles. If daily data from the $16+$ parallel AMIPtype simulations are archived, then in effect ensemble $\mathrm{W}$ is already almost finished; only one more simulation, the one that writes the time step information to W1_STATES, needs to be performed for that ensemble.

(ii) If the number of archived multidecade AMIPtype simulations is less than 16 but greater than 1 , they can still be used, as long as the years from which the 1 June land and atmosphere states are extracted belong to the set of "quiescent" years (i.e., years with little El
Niño or La Niña signal). For the purposes of this experiment, these years are 1951, 1952, 1959, 1960, 1961, 1963, 1977, 1979, 1980, 1981, 1986, 1990, and 1994years for which the Niño-3 anomaly has an absolute value less than 0.5 for the 3 months preceding the initialization date. A group, for example, may have four archived parallel AMIP simulations. Extracting restart files for 1 June 1977, 1979, 1990, and 1994 from each of the four simulations would give a total of 16 sets of initial states for the experiment.

(iii) A more tractable approach for many groups is to access restart files (initial conditions) from a preexisting single $16+$ year simulation. In particular, if such a simulation exists in which SSTs do not vary from year to year (i.e., they are set to seasonally varying climatological values), then the land and atmosphere states produced on 1 June in each of the $16 \mathrm{yr}$ of the simulation can be used to initialize the 16 ensemble members.

(iv) If the only $16+$ year simulation available is an AMIP-type simulation (one with interannually varying SSTs), then the 1 June conditions determined for the different years in this simulation can be used to initialize the June-August 1994 simulations. With this approach [as with approach (ii)], the calendar years for the AMIP simulation are forced to lose their meaning. For example, suppose the restart files produced by an AMIP-type simulation covering 1979-94 are available. The 1 June 1979 atmosphere and land states can be used to initialize one member of ensemble W (and ensembles R and S); the 1 June 1980 states can be used to initialize another ensemble member, and so on.

(v) A common approach to assigning initial conditions to the different members of an ensemble is to run the AGCM for, say, 16 June days and write out the atmosphere and land states at the beginning of each day. Each daily set of fields would then be used as initial conditions. This type of approach, however, is highly undesirable for the present experiment, because the land surface states would not have time to vary much during the short simulation; the initial land conditions among the different members of ensemble $\mathrm{W}$ would not represent the broad range of states that the model is capable of achieving.

Note that given the design of the experiments, the initialization of all land states for ensemble $\mathrm{R}$ and the deeper soil moisture states for ensemble $\mathrm{S}$ is actually irrelevant. Note also that in all cases, the atmosphere may feel a "shock" at the beginning of the $\mathrm{R}$ and $\mathrm{S}$ simulations, because initially it will not be in equilibrium with the prescribed surface state. K02 examined the effect of this shock on $\Omega_{P}$ and concluded that it was small. Nevertheless, the first 8 days or so of each 
3-month simulation is excluded from the data analyses, to avoid its effects.

\section{c. Energy and water balance considerations}

The design of ensembles $\mathrm{R}$ and $\mathrm{S}$ necessarily precludes the maintenance of a strict energy and water budget below the land-atmosphere interface. Note, however, that energy and water in the atmosphere and across the interface are still perfectly conserved; conservation of energy and water is only "neglected" within the land reservoirs themselves. Because these specialized experiments focus solely on the atmospheric response to land conditions through the interface, the lack of conservation below the interface is deemed acceptable.

\section{d. Redundancy of simulations}

If the initial conditions used by simulation W1 (the simulation that wrote out its state variables into file W1_STATES) are also used to initialize one of the members of ensemble R (say, simulation "R1"), then by the construct of the experiment, the weather (and thus the precipitation) generated in simulations $\mathrm{W} 1$ and R1 should be identical. The same holds true if W1's initial conditions are used to initialize a member of ensemble S. Modeling groups can, if they wish, take advantage of this redundancy by using simulation $\mathrm{W} 1$ as a member of both the $\mathrm{R}$ and $\mathrm{S}$ ensembles. In other words, in reality only 15 new simulations need to be performed for both the $\mathrm{R}$ and $\mathrm{S}$ ensembles. (Note that truncation errors may, in fact, allow simulation R1 or S1 to diverge from simulation W1. These truncation effects are irrelevant; the point is that simulation $\mathrm{W} 1$ can properly serve as a member of both the $\mathrm{R}$ and $\mathrm{S}$ ensembles.)

\section{REFERENCES}

Bacmeister, J., P. J. Pegion, S. D. Schubert, and M. J. Suarez, 2000: Atlas of seasonal means simulated by the NSIPP 1 atmospheric GCM. NASA Tech. Memo. 2000-104606, Vol. 17, $194 \mathrm{pp}$.

Boer, G. J., N. A. McFarlane, and M. Lazare, 1992: Greenhouse gas-induced climate change simulated with the CCC secondgeneration general circulation model. J. Climate, 5, 10451077.

Bonan, G. B., K. W. Oleson, M. Vertenstein, S. Levis, Z. Zeng, Y. Dai, R. E. Dickinson, and Z.-L. Yang, 2002: The land surface climatology of the Community Land Model coupled to the NCAR Community Climate Model. J. Climate, 15, 31233149.

Brubaker, K. L., D. Entekhabi, and P. S. Eagleson, 1993: Estimation of continental precipitation recycling. J. Climate, 6, 10771089.

Charney, J., W. J. Quirk, S. H. Chow, and J. Kornfield, 1977:
Comparative study of effects of albedo change on drought in semi-arid regions. J. Atmos. Sci., 34, 1366-1385.

Collins, W. D., and Coauthors, 2004: Description of the NCAR Community Atmosphere Model (CAM 3.0). NCAR Tech. Note NCAR/TN-464+STR. [Available at http://www.ccsm. ucar.edu/models/atm-cam/docs/description/.]

Colman, R., J. Fraser, and L. Rotstayn, 2001: Climate feedbacks in a general circulation model incorporating prognostic clouds. Climate Dyn., 18, 103-122.

Conaty, A. L., J. C. Jusem, L. Takacs, D. Keyser, and R. Atlas, 2001: The structure and evolution of extratropical cyclones, fronts, jet streams, and the tropopause in the GEOS general circulation model. Bull. Amer. Meteor. Soc., 82, 1853-1867.

Cox, P. M., R. A. Betts, C. B. Bunton, R. L. H. Essery, P. R. Rowntree, and J. Smith, 1999: The impact of new land surface physics on the GCM simulation of climate and climate sensitivity. Climate Dyn., 15, 183-203.

Delworth, T. L., and S. Manabe, 1989: The influence of soil wetness on near-surface atmospheric variability. J. Climate, 2, 1447-1462.

Desborough, C. E., 1999: Surface energy balance complexity in GCM land surface models. Climate Dyn., 15, 389-403.

—, A. J. Pitman, and B. J. McAvaney, 2001: Surface energy balance complexity in GCM land surface models, Part 2, Coupled simulations. Climate Dyn., 17, 615-626.

Dirmeyer, P. A., 1994: Vegetation stress as a feedback mechanism in midlatitude drought. J. Climate, 7, 1463-1483.

—, and F. J. Zeng, 1999: An update to the distribution and treatment of vegetation and soil properties in SSiB. COLA Tech. Rep. 78, 25 pp.

Eltahir, E. A. B., and R. L. Bras, 1996: Precipitation recycling. Rev. Geophys., 34, 367-378.

Essery, R. L. H., M. J. Best, R. A. Betts, P. M. Cox, and C. M. Taylor, 2003: Explicit representation of subgrid heterogeneity in a GCM land surface scheme. J. Hydrometeor., 4, 530543.

GFDL Global Atmospheric Model Development Team, 2004: The new GFDL global atmosphere and land model AM2LM2: Evaluation with prescribed SST simulations. J. Climate, 17, 4641-4673.

Gleckler, P., Ed., 1996: AMIP II guidelines. AMIP Newsletter, Vol. 8, PCMDI, Lawrence Livermore National Laboratory, Livermore, $20 \mathrm{pp}$.

Guo, Z.-C., and Coauthors, 2006: GLACE: The Global LandAtmosphere Coupling Experiment. Part II: Analysis. J. Hydrometeor., 7, 611-625.

Hahmann, A. N., and R. E. Dickinson, 1997: RCCM2-BATS model over tropical South America: Applications to tropical deforestation. J. Climate, 10, 1944-1963.

Henderson-Sellers, A., and V. Gornitz, 1984: Possible climatic impacts of land cover transformations, with particular emphasis on tropical deforestation. Climatic Change, 6, 231-258.

Huffman, G. J., R. F. Adler, A. Chang, R. Ferraro, A. Gruber, A. McNab, B. Rudolf, and U. Schneider, 1997: The Global Precipitation Climatology Project (GPCP) Combined Precipitation Dataset. Bull. Amer. Meteor. Soc., 78, 5-20.

Kalnay, E., and Coauthors, 1996: The NCEP/NCAR 40-Year Reanalysis Project. Bull. Amer. Meteor. Soc., 77, 437-471.

Kinter, J. L., and Coauthors, 1997: The COLA atmospherebiosphere general circulation model. Volume 1: Formulation. COLA Tech. Rep. 51, 46 pp.

Koster, R., and M. Suarez, 1996: Energy and water balance cal- 
culations in the mosaic LSM. NASA Tech. Memo. 104606, Vol. 9, 59 pp.

Koster, R. D., and M. J. Suarez, 2001: Soil moisture memory in climate models. J. Hydrometeor., 2, 558-570.

$\longrightarrow$, and — 2004: Suggestions in the observational record of land-atmosphere feedback operating at seasonal time scales. J. Hydrometeor., 5, 567-572.

—_, P. A. Dirmeyer, A. N. Hahmann, R. Ijpelaar, L. Tyahla, P. Cox, and M. J. Suarez, 2002: Comparing the degree of landatmosphere interaction in four atmospheric general circulation models. J. Hydrometeor., 3, 363-375.

—, M. J. Suarez, R. W. Higgins, and H. M. Van den Dool, 2003: Observational evidence that soil moisture variations affect precipitation. Geophys. Res. Lett., 30, 1241, doi:10.1029/ 2002 GL016571.

— - and Coauthors, 2004: Regions of strong coupling between soil moisture and precipitation. Science, 305, 1138-1140.

Kowalczyk, E. A., J. R. Garratt, and P. B. Krummel, 1994: Implementation of a soil-canopy scheme into the CSIRO GCMRegional aspects of the model response. CSIRO Atmospheric Research Tech. Paper 32, 59 pp.

Lau, K.-M., and W. Bua, 1998: Mechanisms of monsoon-Southern Oscillation coupling, insights from GCM experiments. Climate Dyn., 14, 759-779.

McFarlane, N. A., G. J. Boer, J.-P. Blanchet, and M. Lazare, 1992: The Canadian Climate Centre second-generation general circulation model and its equilibrium climate. J. Climate, 5, 1013-1044.

McGregor, J. L., 1996: Semi-Lagrangian advection on conformalcubic grids. Mon. Wea. Rev., 124, 1311-1322.

— and M. R. Dix, 2001: The CSIRO conformal-cubic atmospheric GCM. IUTAM Symposium on Advances in Mathematical Modeling of Atmosphere and Ocean Dynamics, P. F. Hodnett, Ed., Kluwer, 197-202.

Milly, P. C. D., and A. B. Shmakin, 2002: Global modeling of land water and energy balances. Part I: The Land Dynamics (LaD) model. J. Hydrometeor., 3, 283-299.

Mocko, D. M., and Y. C. Sud, 2001: Refinements to SSiB with an emphasis on snow-physics: Evaluation and validation with GSWP and Valdai data. Earth Interactions, 5. [Available online at http://EarthInteractions.org.]

Moorthi, S., H.-L. Pan, and P. Caplan, 2001: Changes to the 2001 NCEP operational MRF/AVN Global Analysis/Forecast System. National Weather Service Office of Meteorology Technical Procedures Bulletin 484, 14 pp.

Nozawa, T., S. Emori, A. Numaguti, Y. Tsushima, T. Takemura, T. Nakajima, A. Abe-Ouchi, and M. Kimoto, 2001: Projections of future climate change in the 21st century simulated by the CCSR/NIES CGCM under the IPCC SRES scenarios. Present and Future of Modeling Global Environmental Change: Toward Integrated Modeling, T. Matsuno and H. Kida, Eds., TERRAPUB, 15-28.

Numaguti, A., 1993: Dynamics and energy balance of the Hadley circulation and the tropical precipitation zones: Significance of the distribution of evaporation. J. Atmos. Sci., 50, 18741887.

, M. Takahashi, T. Nakajima, and A. Sumi, 1997: Description of CCSR/NIES Atmospheric General Circulation Model. CGER's Supercomputer Monograph Report, 3, NIES, 1-48.

Oglesby, R. J., and D. J. Erickson III, 1989: Soil moisture and the persistence of North American drought. J. Climate, 2, 13621380.

Oleson, K. W., and Coauthors, 2004: Technical description of the Community Land Model (CLM). NCAR Tech. Note NCAR/ TN-461+STR, 173 pp. [Available online at http://www. cgd.ucar.edu/tss $/ \mathrm{clm} /$ distribution/clm $3.0 /$ TechNote/ CLM_Tech_Note.pdf.]

Pan, H. L., and L. Mahrt, 1987: Interaction between soil hydrology and boundary layer development. Bound.-Layer Meteor., 38, 185-202.

Pope, V. D., M. L. Gallani, P. R. Rowntree, and R. A. Stratton, 2000: The impact of new physical parameterizations in the Hadley Centre climate model: HadAM3. Climate Dyn., 16, 123-146.

Reale, O., P. A. Dirmeyer, and C. A. Schlosser, 2002: Modeling the effect of land surface evaporation variability on precipitation variability. Part II: Time- and space-scale structure. $J$. Hydrometeor., 3, 451-466.

Shukla, J., and Y. Mintz, 1982: Influence of land-surface evapotranspiration on the earth's climate. Science, 215, 1498-1501.

Sud, Y. C., and G. K. Walker, 1999a: Microphysics of Clouds with the Relaxed Arakawa-Schubert Cumulus Scheme (McRAS). Part I: Design and evaluation with GATE Phase III data. J. Atmos. Sci., 56, 3196-3220.

— and $-1999 \mathrm{~b}$ : Microphysics of Clouds with the Relaxed Arakawa-Schubert Cumulus Scheme (McRAS). Part II: Implementation and performance in GEOS II GCM. $J$. Atmos. Sci., 56, 3221-3240.

Trenberth, K. E., 1999: Atmospheric moisture recycling: Role of advection and local evaporation. J. Climate, 12, 1368-1381.

Verseghy, D. L., 1991: CLASS-A Canadian land surface scheme for GCMs. I. Soil model. Int. J. Climatol., 11, 111-133.

— 2000: The Canadian land surface scheme (CLASS): Its history and future. Atmos.-Ocean, 38, 1-13.

_ - N. A. McFarlane, and M. Lazare, 1993: CLASS-A Canadian land surface scheme for GCMs, II, Vegetation model and coupled runs. Int. J. Climatol., 13, 347-370.

Xue, Y., P. J. Sellers, J. L. Kinter, and J. Shukla, 1991: A simplified biosphere model for global climate studies. J. Climate, 4, 345-364.

- , F. J. Zeng, K. E. Mitchell, Z. Janjic, and E. Rogers, 2001: The impact of land surface processes on the simulation of the U.S. hydrological cycle: A case study of the 1993 flood using the SSiB land surface model in the NCEP Eta regional model. Mon. Wea. Rev., 129, 2833-2860.

- , H.-M. H. Juang, W.-P. Li, S. Prince, R. DeFries, Y. Jiao, and R. Vasic, 2004: Role of land surface processes in monsoon development: East Asia and West Africa. J. Geophys. Res., 109, D03105, doi:10.1029/2003JD003556.

Zhong, A., R. Coleman, N. Smith, M. Naughton, L. Rikus, K. Puri, and F. Tseitkin, 2001: Ten-year AMIP 1 climatologies from versions of the BMRC Atmospheric Model. Bureau of Meteorology BMRC Research Rep. 83, 34 pp. 